\title{
Development of Individual Tree Growth and Yield Model Across Multiple Contrasting Species Using Non-parametric and Parametric Methods in the Hyrcanian Forests of Northern Iran
}

Seyedeh Kosar Hamidi

Sari Agricultural Sciences and Natural Resources University

Aaron Weiskittel

The University of Maine

Mahmoud Bayat ( $\square$ mbayat@rifr-ac.ir)

Research Institute of Forests and Rangelands https://orcid.org/0000-0003-4348-3228

Asghar Fallah

Sari Agricultural Sciences and Natural Resources University

Research

Keywords: diameter growth, height, survival, ingrowth, Artificial Neural Network, Mixed models, Permanent sample plots

Posted Date: September 9th, 2020

DOI: https://doi.org/10.21203/rs.3.rs-72348/v1

License: (c) (1) This work is licensed under a Creative Commons Attribution 4.0 International License.

Read Full License 
1. Sari Agriculture Sciences and Natural Resource University, Sari, Mazandaran, Iran 5

2. Center for Research on Sustainable Forests, University of Maine, Orono, ME, USA 6

3. Research Institute of Forests and Rangelands, Agricultural Research, Education, and Extension 7

Organization (AREEO), Tehran, Iran. $\quad 8$

* Corresponding author: Mbayat@rifr-ac.ir (M. Bayat) 99

$\begin{array}{ll}\text { Abstract } & 11\end{array}$

$\begin{array}{ll}\text { Background } & 12\end{array}$

The Hyrcanian forests of Iran contain many species-rich communities that can only be 13 maintained through an understanding of the renewal and development of these forests. 14 Located in the Jojadeh section of the Farim forest in northern Iran, individual tree growth of 15 five distinct species [(Oriental beech (Fagus orientalis Lipsky), chestnut-leaved oak 16 (Quercus castaneifolia Coss. ex J.Gay), Persian maple (Acer velutinum Boiss.), common 17 hornbeam (Carpinus betulus L.) and Caucasian alder (Alnus subcordata C.A.Mey.)] were 18 measured on 313 permanent sample plots (0.1 ha) over a 10-year period (2003-2013). 19

$\begin{array}{ll}\text { Methods } & 20\end{array}$

In this analysis, various tree-level predictions were investigated using the available data with 21 application of parametric models and two artificial neural networks (i.e., the multilayer 22 perceptron (MLP) and radial basis function (RBF) networks). 23

$\begin{array}{ll}\text { Results } & 24\end{array}$

Individual tree diameter growth models showed a robust negative relationship with basal area 25 in larger trees (BAL), which was relatively consistent across species. A total height model 26 
indicated that the examined species did not differ for a given set of covariates. In the survival 27 model, the survival probability of Oriental beech was lower than the other species, while the more accurately than the RBF. Furthermore, the models based on the MLP were also superior to the parametric individual tree models developed using mixed-effect regression.

\section{Conclusion}

The use of these developed models in forest planning and management is imperative, but

Keywords: diameter growth, height, survival, ingrowth, Artificial Neural Network, Mixed

\section{Introduction}

Hyrcanian forests are the only commercial forests where temperate broad-leaved tree species exist today in Iran. Covering an area of approximately 1.85 million ha, the Hyrcanian forests account for approximately $15 \%$ of Iranian forests and $1.1 \%$ of the country's total area.

(Alnus subcordata C.A.Mey.) are among the main tree species in these forests. The 
resilience of this important forest ecosystem to support and benefit human livelihoods in the

region. Whereas economic planning without consideration for sustaining renewable natural

resources can lead to their degradation that can ultimately contribute to the extinction of

nations and civilizations (Hatfild, 2015), decision-makers are no longer solely concerned

about economics and do increasingly take a broader, more holistic management perspective

(Vanclay, 1994).

In forestry, decision-making is the essence of a management plan that includes

management objectives in a forest area (Bayat et al., 2013). Because multiple forest management objectives often conflict at the landscape scale, a spatial approach to planning

uses a modeling technique that adapts spatially explicit stand management objectives to

minimize the conflicts at the landscape scale (Baskent \& Keles, 2005). In addition to high-

To obtain the most reliable information on the likely future state of a forest, planners rely on forecasts from growth and product models that are widely employed in forest management alternative management options/scenarios and have thus become a key element in sustainable forest management planning (Burkhart, 1990; Vanclay, 1994; Bayat et al., 2013). For example, sub-models for individual tree diameter/height growth, survival, and ingrowth 74 enabled the predictions of stand density and diameter distributions needed to guide the 75 management of uneven-aged forests in Finland (Pukkala et al., 2009, 2012). Further, harvest 76 intensities were based on height, survival, and growth of the regeneration in uneven mixed 
softwood stands in Finland to ensure sufficient survival and growth of small spruces (Picea spp.), intolerant birch (Betula spp.) and pine (Pinus spp.) to maintain the species composition 79 of the current selection stands (Eerikainen et al., 2014). Finally, mixed-effects regression 80 models were recently developed to project the distance-independent individual tree growth 81 and yield for uneven-aged forests in northern Iran managed under selection systems (Kalbi et 82 al., 2019). In addition to the mentioned studies, other researches such as Ahmadi et al. (2016, 83 2020) have developed additional tree-level statistical models for the Hyrcanian forests.

To more fully understand the dynamics of forests, it is often not sufficient to solely 85 model the overall growth of forest stands, but commonly more detailed individual-based 86 modeling approaches are needed that effectively discriminate among several growth 87 components (Vanclay 1994). This is especially true to support uneven-aged forest 88 management in mixed natural stands, the following set of individual tree growth models is 89 essential: diameter/height growth, tree mortality or survival, and estimates of ingrowth 90 (Trasobares et al. 2004; Bayat et al., 2013). The models can be developed using a variety of 91 statistical techniques, which are further explained below.

The mixed-effects model is a parametric method for addressing hierarchical data. 93 Examples of grouped data are individuals within spatially explicit subgroups, such as sample 94 trees within forest sample plots; observations of a split-plot or a block in a controlled 95 experiment; and repeated measurements of any subjects, such as plants or permanent sample 96 plots. It is quite common that the groups of the data represent only a sample from a 97 population of groups, while general interest is often in making the inference about the entire 98 population of groups. In those situations, the group effects are naturally treated as random 99 variables, which leads to the mixed-effects model, also called mixed or random-effects 100 regression. These mixed models have been extensively used and have now become the 101 standard for growth and yield modeling (Weiskittel et al. 2011). Additional benefits of 
random group effects over the fixed effects are that the number of observations per group can

be small; even one observation per group may be enough for satisfactory estimation accuracy,

In addition to mixed-effects regression techniques, artificial neural networks (ANNs) is a problems in various fields, including communication memory, optimization, prediction,

Vieira et al. 2018), determining volume and biomass of individual trees (Pereira et al, 2019),

Few studies have investigated how well traditional parametric mixed-effects compare to 
using both approaches clearly demonstrated the great potential of AI techniques compared to

mixed models and underscored the utility of ANN-based models to handle manifold

information to accurately predict tree-level attributes (Pereira et al. 2019). However,

nonparametric methods like ANN may have important limitations for application in a

regional forest growth and yield modeling context, namely inability to extrapolate beyond the

fitting data, potential inconsistency with biological expectations, and more difficult

transferability to other potential users. To our knowledge, no comprehensive study has

compared the tree-level growth and yield results from parametric mixed-effects regression

models to those from ANNs to date, particularly in uneven-aged and mixed forests like those in the Hyrcanian forests of Iran.

ANNs used in this study consisted of two architectures that are commonly used for solving difficult engineering problems (Walling et al., 2001; Zhu et al, 2007; Bayat et al.,

2020): the feedforward multilayer perceptron (MLP) and the radial base function (RBF)

networks. Both methods give robust estimates (Reis et al., 2018; Van Dao et al., 2020) and are able to approximate a variety of nonlinear functions (Benali et al. 2019). The number of layers and neurons in each hidden layer is of great importance in designing the network. The number of neurons in the input and output layers is equal to the number of input and output variables under investigation. The challenging task is to determine the number of hidden layers and the number of neurons in each hidden layer. The ANNs in this study were trained with back-propagation algorithms that used $70 \%$ of input-output data records for model training and the remainder for model testing (Benali et al. 2019).

To manage mixed uneven-aged forests with the selection system, reliable predictive

models of diameter/height growth, survival/mortality rates of trees, and ingrowth of regeneration are needed to guide harvest intensities and residual basal areas to ensure a sustainable development of trees through the diameter distribution. In this study, we 
parameterized these various individual tree growth models using mixed models and ANN to

determine which approach provided the best model accuracy. Further, the primary goal was

an accurate and appropriate method for predicting diameter/height growth, survival /mortality

rates of trees, and ingrowth of regeneration for the most important and economically valuable

\section{Materials and methods}

\subsection{Study area}

This study was carried out in the Jojadeh district, which is one of five sections covered by forestry development projects in the Farim forest. The Jojadeh section is located on the southern part of the Sari, the capital city of the Mazandaran province on the slopes of the northern Alborz Mountains in the Dodangeh district (Figure 1). The section covers an area of 3550.2 ha with minimum and maximum altitudes of 782 and $1750 \mathrm{~m}$, respectively. The climate of this forest is classified as humid with an annual rainfall of $832.9 \mathrm{~mm}$ and an

Oriental beech (Fagus orientalis Lipsky), chestnut-leaved oak (Quercus castaneifolia Coss. 


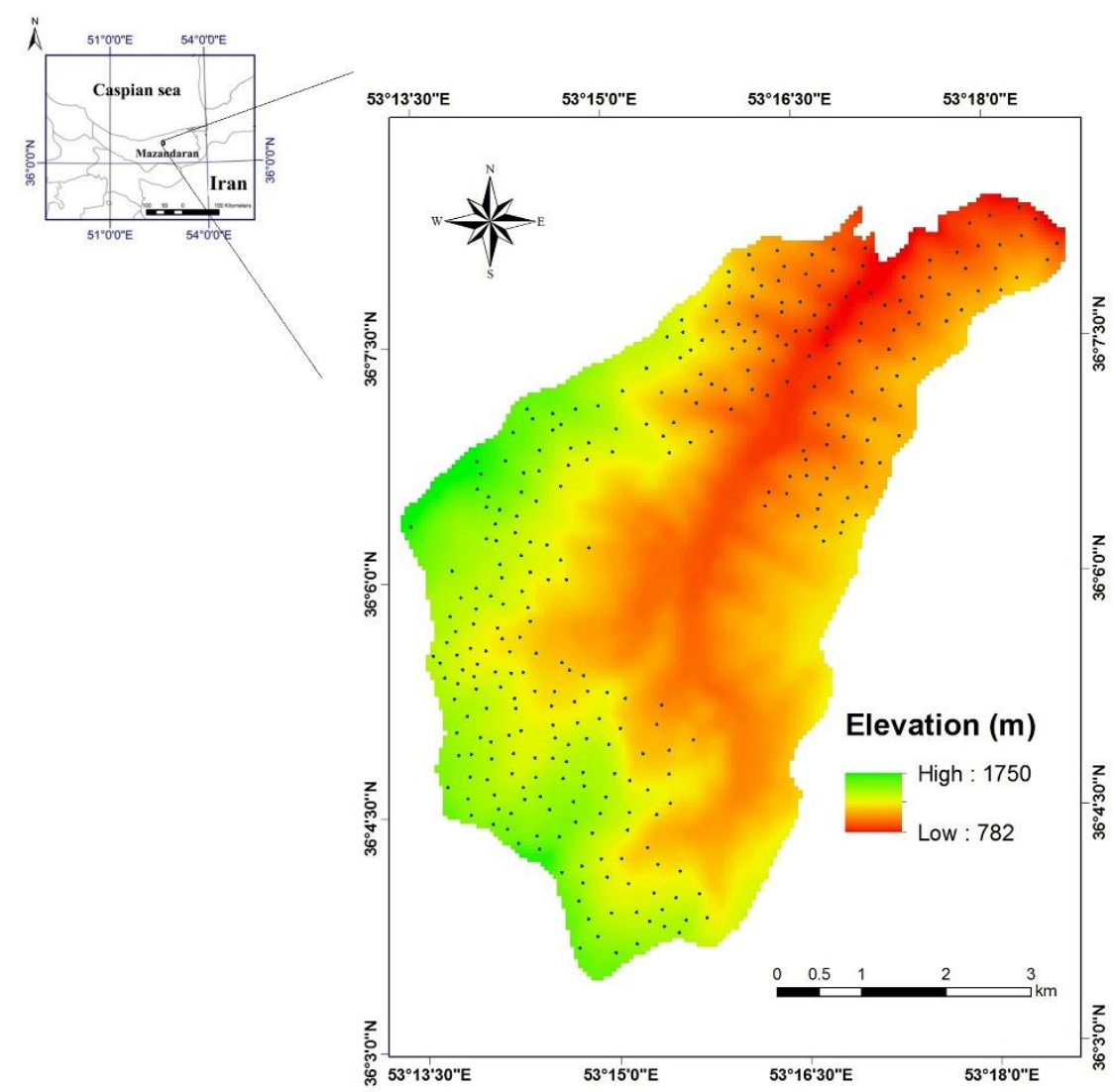

Figure 1. Overview of the study area in northern Iran and approximate location of plots used

\subsection{Study method}

In 2003, 313 circular permanent sample plots (0.1 ha) were systematically laid out using an inventory grid $(200 \mathrm{~m} \times 150 \mathrm{~m})$ in the Jojadeh district. After locating the plot centers in the field, the slope of each plot was determined, and the radius of the sample plot was slope corrected. In each plot, the center was permanently monumented and each tree within the plot received a number that was painted at breast height $(1.3 \mathrm{~m})$. The DGPS device (RTK model with an accuracy of approximately 1-5 $\mathrm{cm}$ (RMS)) was used to record the position of all sample plots (Bettinger et al., 2019). The DBH of all live trees with a diameter $>12.5 \mathrm{~cm}$ was measured using a caliper and recorded by species and All data, including slope, aspect, etc., 
mortality of any previously tallied tree and ingrowth of trees beyond the diameter threshold

were noted.

Data

A total of 4832 trees of which 2878 were Oriental beech, 838 common hornbeam, 187

oak, 417 Caucasian alder, 80 Persian maple and 432 Other trees predominantly Acer carpinifolia. All of these observations across the five primary species were available for modeling diameter growth. Height was modeled using 626 pairs of diameter and height, while a total of 5852 and 1340 trees were used for survival and regeneration modeling, respectively.

Due to the uneven structure of most stands in this forest, the thickest and closest tree to the center of the plot were selected for measurement, which was accomplished using a Sunto 199 clinometer and calculated from the following formula (Equation. 1):

$$
\mathrm{H}=\mathrm{d}[\tan \alpha-(\tan \beta)]
$$

Where $H$ : the height of the tree $(m), d$ : the horizontal distance to the tree $(m), \tan \alpha$ and $\tan \beta$ :

For modeling the 10-year diameter increment $\left(\mathrm{DBH}_{2013}-\mathrm{DBH}_{2003}\right)$ in this study, the basal area (BA) and basal area of trees larger than the subject tree (BAL) as well as its 
predictors of diameter growth in both even-aged (Adame et al. 2008, Uzoh and Oliver 2008)

and uneven-aged stands (Pukkala et al. 2009); and (3) physiographic factors including slope,

aspect, altitude and transformation of these variables with natural log-transformed diameter

growth as the dependent variable (Vanclay, 1994), Linear mixed-effect regression was used

to model the diameter increment following Lhotka, and Loewenstein (2011) that incorporated

species as the random variable (Kuehne et al, 2020).

Due to errors in tree height measurements associated with the first inventory, only a

static total height model associated with the second inventory could be developed. The static

height models were developed based on the relationship between tree height and DBH from

626 trees (i.e., the largest diameter and nearest tree to the center in each sample plot). Twenty

alternative nonlinear DBH to height model types were fitted and evaluated in this study from

which 11 models were two-parameter and nine were three-parameter models.

The mortality model was based on the number of trees that survived or died between

2003 and 2013 and modeled by species using logistic regression. The explanatory variables

evaluated were tree size (DBH and different derivatives) and competition factors (BA, BAL,

$P i=\frac{1}{1+e^{-[b(0)+b(1) \times x(1)+b(2) \times x(2)+\cdots+b(n) \times x(n)]}}$

Where $P_{i}$ represents the possibility of tree mortality for threshold $i, b_{0}-b_{n}$ are parameters to be estimated and $\mathrm{x}_{(1)}-\mathrm{x}_{(\mathrm{n})}$ are descriptive variables.

The regeneration/ingrowth model used the number of trees that exceeded the diameter threshold of $12.5 \mathrm{~cm} \mathrm{DBH}$ as the response variable and that was regressed against stand total basal area. Based on the data availability and desired use in future projections, some additional explanatory variables for predicting the number of ingrowth trees per hectare were 
plot; (iv) physiographic factors; and (v) transformations of basal area $\left(\mathrm{m}^{2} \mathrm{ha}^{-1}\right)$. These were

all used in a Poisson generalized linear model (GLM) (Equation. 3).

$\ln (\mathrm{IN})=\beta_{0}+\beta_{1} \mathrm{x}_{1}+\beta_{2} \mathrm{x}_{2}+\ldots+\beta_{\mathrm{n}} \mathrm{x}_{\mathrm{n}}$

The systematic linear predictor is a multiplication of a parameter vector $\beta$ and an explanatory

variable design matrix $\mathrm{X}$ ( $\mathrm{Li}$ et al, 2011). All computations and modeling were done

employing the R software using the lme and nlme packages (Pinheiro et al. 2020) similar to

Bayat et al. (2020).

Artificial Neural Network (ANN)

Prior to training, all input and output data were normalized (Nagy et al., 2002). The ANN-structure was iteratively altered by changing the number of hidden nodes. The structure that produced the least amount of error (difference between modeled and observed values) was selected for further testing at a later stage. All calculations were analyzed in

STATISTICA software.

Common criteria for assessing the goodness-of-fit of model predictions are the

$\mathrm{RMSE}=\sqrt{\frac{\sum_{i=1}^{n}\left(e s t_{i}-o b s_{i}\right)^{2}}{n}}$

Relative $\mathrm{RMSE}=100 *(\mathrm{RMSE} / \mathrm{mean}$ observation value $)$ 
$\mathrm{BIAS}=\frac{\sum_{i=1}^{n}\left(e s t_{i}-o b s_{i}\right)}{n}$

Relative $\mathrm{BIAS}=100 *(\mathrm{BIAS} / \mathrm{mean}$ observation value $)$

where $e s t_{i}$ and $o b s_{i}$ are the $i^{\text {th }}$ estimate and observation, respectively, and $n$ is the number of

observations. For evaluation, we performed cross-validation by randomly selecting $70 \%$ of

the data as the training dataset and $30 \%$ as the evaluation dataset.

\section{Results}

The data covered a wide range of conditions typical for the region with the descriptive statistics given in Table 1.

Table1. Descriptive statistics of data used in the growth model

\begin{tabular}{|c|c|c|c|c|}
\hline Variable & Mean & Maximum & Minimum & Standard deviation \\
\hline \multicolumn{5}{|c|}{ Tree-level } \\
\hline Diameter $(\mathrm{cm})$ & 37 & 160 & 12.5 & 22 \\
\hline Total height $(\mathrm{m})$ & 16.55 & 33.32 & 13.82 & 2.66 \\
\hline Diameter growth $\left(\mathrm{cm} \mathrm{yr}^{-1}\right)$ (train) & 1.94 & 7.45 & 0 & 1.16 \\
\hline Diameter growth $\left(\mathrm{cm} \mathrm{yr}^{-1}\right)$ (test) & 1.98 & 8 & 0 & 1.17 \\
\hline Survival (train) & 0.98 & 1 & 0 & 0.02 \\
\hline Survival (test) & 0.98 & 1 & 0 & 0.02 \\
\hline \multicolumn{5}{|c|}{ Stand-level } \\
\hline Stem density $\left(\#\right.$ ha $\left.^{-1}\right)$ & 212 & 560 & 60 & 91.7 \\
\hline Ingrowth $\left(\#\right.$ ha $\left.^{-1} \mathrm{yr}^{-1}\right)$ (train) & 7.5 & 12 & 6 & 1.13 \\
\hline Ingrowth $\left(\#\right.$ ha $\left.^{-1} \mathrm{yr}^{-1}\right)$ (test) & 8 & 12 & 5 & 1.15 \\
\hline Total basal area $\left(\mathrm{m}^{2} \mathrm{ha}^{-1}\right)$ & 22.8 & 48.8 & 3.8 & 10.3 \\
\hline Elevation & 1178.2 & 1650.0 & 815.0 & 234.1 \\
\hline Slope & 31.9 & 70.0 & 5.0 & 12.6 \\
\hline
\end{tabular}


The diameter growth of most trees ranged between $0-8 \mathrm{~cm}$ in the 10 -year period. A

linear mixed-effect model was employed for modeling of the diameter growth and the best performing model is presented in Equation 8:

$\mathrm{Id}=-1.64+\mathrm{u}_{\mathrm{j}}+0.03(\mathrm{DBH})-0.00015\left(\mathrm{DBH}^{2}\right)+0.0032(\mathrm{BA})-0.010(\mathrm{BAL})-0.00016\left(\mathrm{DBH}^{*} \mathrm{BAL}\right)$ +0.00014 (Slope) $-0.03 \sin ($ Aspect $)+0.14 \cos ($ Aspect $)+\mathrm{e}_{\mathrm{ij}}$

Where Id is the diameter growth in a 10 -year period; $\mathrm{u}_{\mathrm{j}} \sim \mathrm{N}\left(0, \sigma_{\mathrm{u}}{ }^{2}\right)$ represents the random effect species; DBH is the diameter at breast height $(\mathrm{cm})$; Square of $\mathrm{DBH}(\mathrm{cm}), \mathrm{BA}$ is the stand basal area $\left(\mathrm{m}^{2} \mathrm{ha}^{-1}\right)$; BAL is the basal area of larger trees in the plot when compared to the subject tree $\left(\mathrm{m}^{2} \mathrm{ha}^{-1}\right)$. The variance and standard deviation for the random factor of species were 1.79 and 2.83 , respectively. Results also showed that the correlation between growth rate and BAL was negative i.e. the diameter growth decreased with an increase in this index. 284 The RMSE, bias, and $\mathrm{R}^{2}$ were $1.11,0.12$, and 0.20 , respectively

Results of five MLP- and RBF-based ANNs showed that the RBF-based models gave better results the superior MLP-based model resulted in an RMSE of $0.06 \mathrm{~cm}$, indicating that the predicted average diameter growth is close to the measured diameter growth (Table 2). In Table 2, only the models with high accuracy are given, while all ANNs fitted are given in the Supplemental Materials (Table S1 and S2). Also, Fig. 2 shows the relationship between the actual and predicted diameter growth for all species by the parametric (mixed-effect regression) and non-parametric methods (ANN).

Table 2. Characteristics of the superior MLP-based ANNs for individual tree diameter growth and 


\begin{tabular}{cccccccccc}
\hline sample & Structure & Algorithm & $\begin{array}{c}\text { Error } \\
\text { Function }\end{array}$ & $\begin{array}{c}\text { Hidden } \\
\text { activation }\end{array}$ & $\mathbf{R}^{2}$ & RMSE & \%RMSE & BIAS & \%BIAS \\
\hline Train & MLP 13-6-1 & BFGS 57 & SOS & Tanh & 0.55 & 0.93 & 4.79 & 0.1 & 0.51 \\
Test & MLP 13-6-1 & BFGS 57 & SOS & Tanh & 0.53 & 0.79 & 3.98 & 0.06 & 0.30 \\
\hline
\end{tabular}

MLP = multilayer perceptron (10-4-1 implies $10=$ number of input layers; 4 = number of hidden layers; and $1=$

number of output layer); RBF = radial basis function; BFGS = Broyden-Fletcher-Goldfarb-Shanno; RBFT =

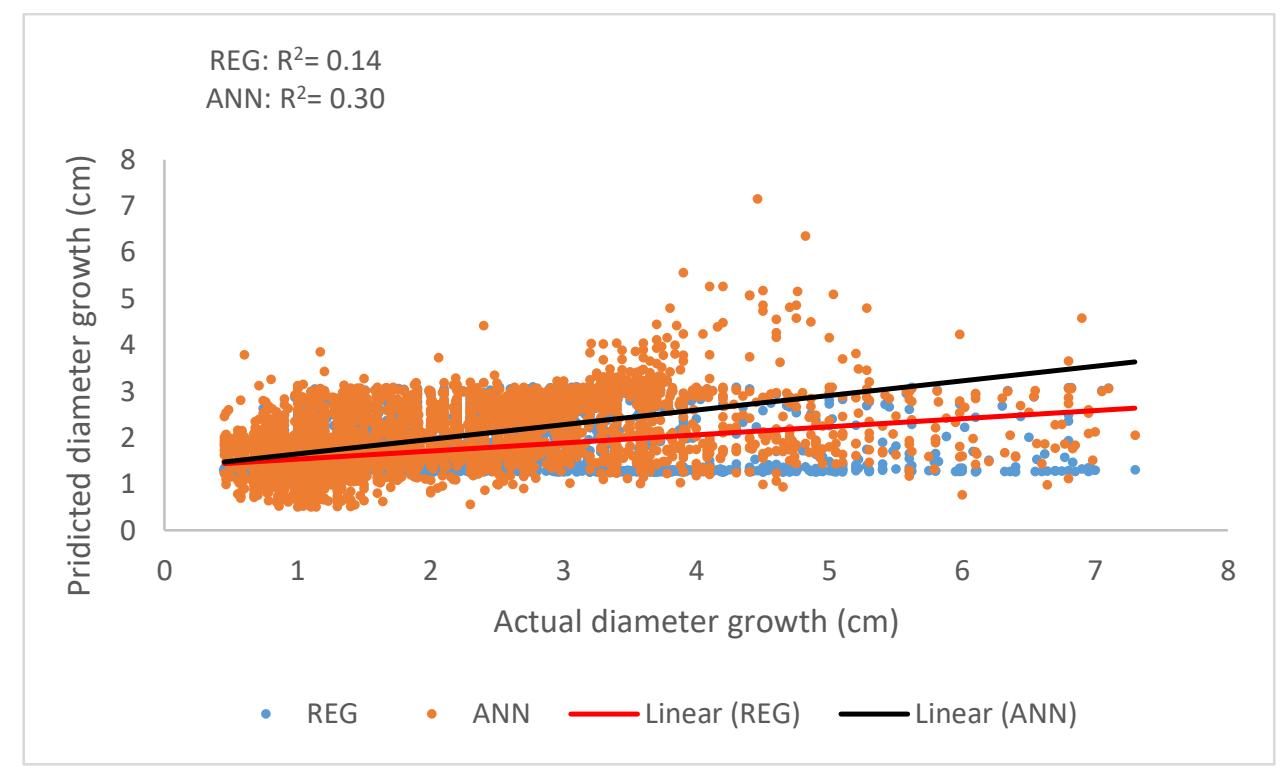

Figure 2. Graphical presentation of measured and predicted tree diameter growth by the parametric

The following individual tree data were used to fit tree height models using tree diameter 
Table 3. Descriptive statistics of trees' DBH $(\mathrm{cm})$ and height $(\mathrm{m})$ by species in the study area

\begin{tabular}{|c|c|c|c|c|c|c|c|c|c|c|c|c|}
\hline Descriptive & \multicolumn{6}{|c|}{$\mathrm{DBH}(\mathrm{cm})$} & \multicolumn{6}{|c|}{ Height (m) } \\
\hline Species & Fagus & Carpinus & Quercus & Alnus & Acer & $\begin{array}{c}\text { Other } \\
\text { trees }\end{array}$ & Fagus & Carpinus & Quercus & Alnus & Acer & $\begin{array}{l}\text { Other } \\
\text { trees }\end{array}$ \\
\hline Mean & 63.2 & 67.5 & 68.1 & 71.6 & 57.2 & 53.4 & 27.7 & 24.5 & 26.6 & 27.6 & 22.3 & 19.5 \\
\hline Maximum & 138 & 122 & 110 & 135 & 130 & 122 & 40.5 & 36 & 39 & 40.5 & 36.3 & 38.4 \\
\hline Minimum & 13 & 25 & 18 & 10 & 13 & 14 & 7.5 & 12.5 & 8 & 7 & 10 & 7 \\
\hline $\begin{array}{l}\text { Standard } \\
\text { Deviation }\end{array}$ & 29.3 & 23.1 & 23.4 & 30.8 & 42.9 & 33.9 & 7.3 & 5.2 & 6.6 & 7.3 & 8.9 & 8.3 \\
\hline Number & 398 & 98 & 51 & 78 & 19 & 33 & 398 & 98 & 51 & 78 & 19 & 33 \\
\hline
\end{tabular}

Of the ANN models evaluated for tree height, the MLP-based ANN that contained seven

hidden layers was the superior model that resulted in an RMSE of $4.81 \mathrm{~m}$ (Table 4). In Table

4, only the models with high accuracy are given, while the results of all ANN are given in the

Supplemental Materials (Table S3 and S4). However, predictions using the best ANN and

mixed model were nearly identical across the range of tree sizes examined (Figure 3).

Table 4. Characteristics of the superior MLP-based ANNs for individual tree height and associated

\begin{tabular}{cccccccccc}
\hline Sample & Structure & Algorithm & $\begin{array}{c}\text { Error } \\
\text { Function }\end{array}$ & $\begin{array}{c}\text { Hidden } \\
\text { activation }\end{array}$ & R $^{2}$ & RMSE & \%RMSE & BIAS & \%BIAS \\
\hline Train & MLP 3-4-1 & BFGS 15 & SOS & Identity & 0.74 & 4.89 & 18.53 & 0.0003 & 0.001 \\
\hline Test & MLP 3-4-1 & BFGS 15 & SOS & Identity & 0.86 & 2.86 & 10.55 & 0.09 & 0.34 \\
\hline
\end{tabular}

MLP $=$ multilayer perceptron (3-7-1 implies $3=$ number of input layers; $7=$ number of hidden layers;

and $1=$ number of output layer); RBF = radial basis function; FGS = Broyden-Fletcher-Goldfarb-

Shanno; RBFT = Radial Basis Function Training; SOS = Symbiotic Organisms Search 


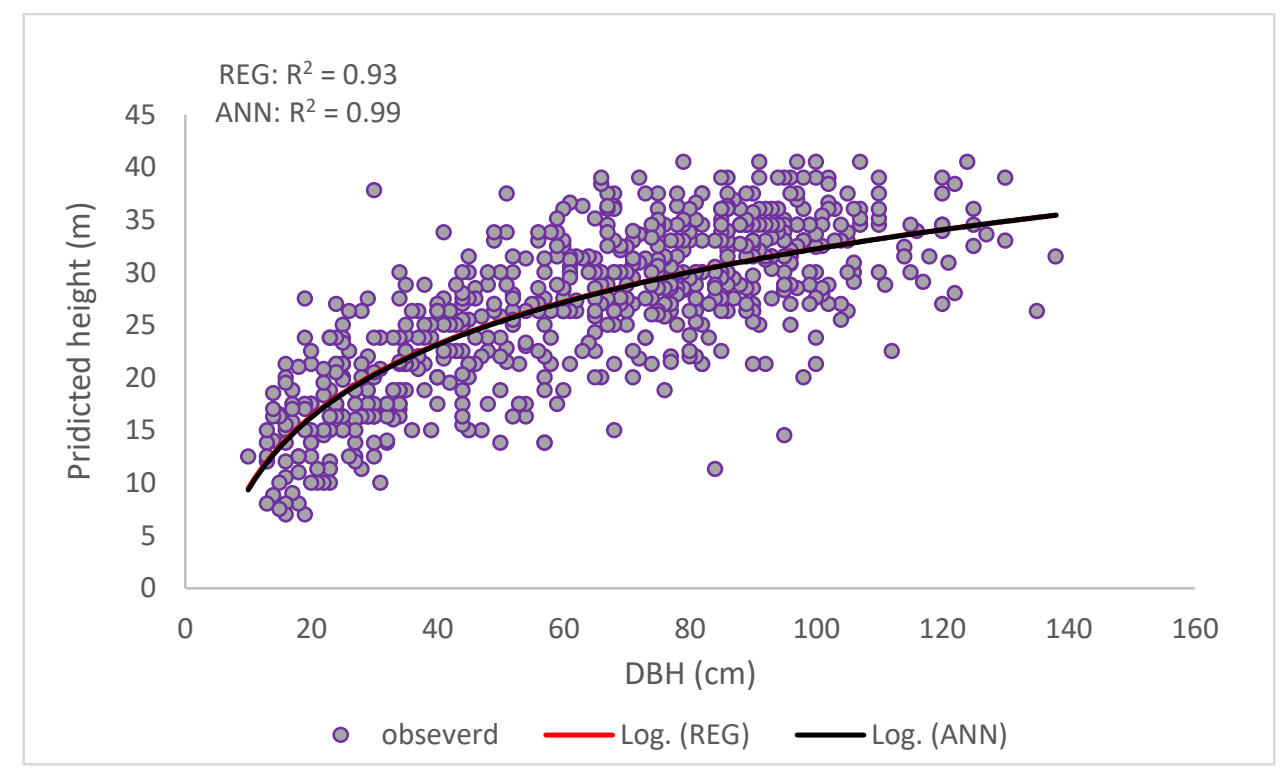

Figure 3. Regression model of diameter-height by the parametric (mixed-effect regression (red

$$
\text { line)) and non-parametric methods (ANN (black line)) }
$$

\section{Individual tree survival growth (mortality) model}

In the mortality model, we considered the survival of trees to be a one and dead trees

are a zero with a binary logistic regression was used to estimate the survival model. Equation

$$
Y=\frac{1}{1+\exp ^{(4+0.17 D B H-8.01 B A-1.10 B A L)}}
$$

The results of the neural network show that the MLP-based network of tree survival had

an RMSE of 0.28 and a bias of 0.011 and performed better than the RBF-based network

(Table 5 and Fig 4). In Table 5, only the models with high accuracy are presented, while all

Table 5. Characteristics of the superior RBF and MLP-based ANNs for individual tree survival and 


\begin{tabular}{cccccccccc}
\hline Sample & Structure & Algorithm & $\begin{array}{c}\text { Error } \\
\text { Function }\end{array}$ & $\begin{array}{c}\text { Hidden } \\
\text { activation }\end{array}$ & $\mathbf{R}^{\mathbf{2}}$ & RMSE & \%RMSE & BIAS & \% BIAS \\
\hline Train & MLP 5-7-1 & BFGS 132 & SOS & Logistic & 0.27 & 0.35 & 35.77 & 0.005 & 0.01 \\
\hline Test & MLP 5-7-1 & BFGS 132 & SOS & Logistic & 0.36 & 0.28 & 28.01 & 0.011 & 1.19 \\
\hline MLP $=$ multilayer perceptron (5-7-1 implies 5 = number of input layers; 7 - number of hiden layers;
\end{tabular}

and $1=$ number of output layer); RBF = radial basis function; BFGS = Broyden-Fletcher-Goldfarb-

Shanno; RBFT = Radial Basis Function Training; SOS = Symbiotic Organisms Search

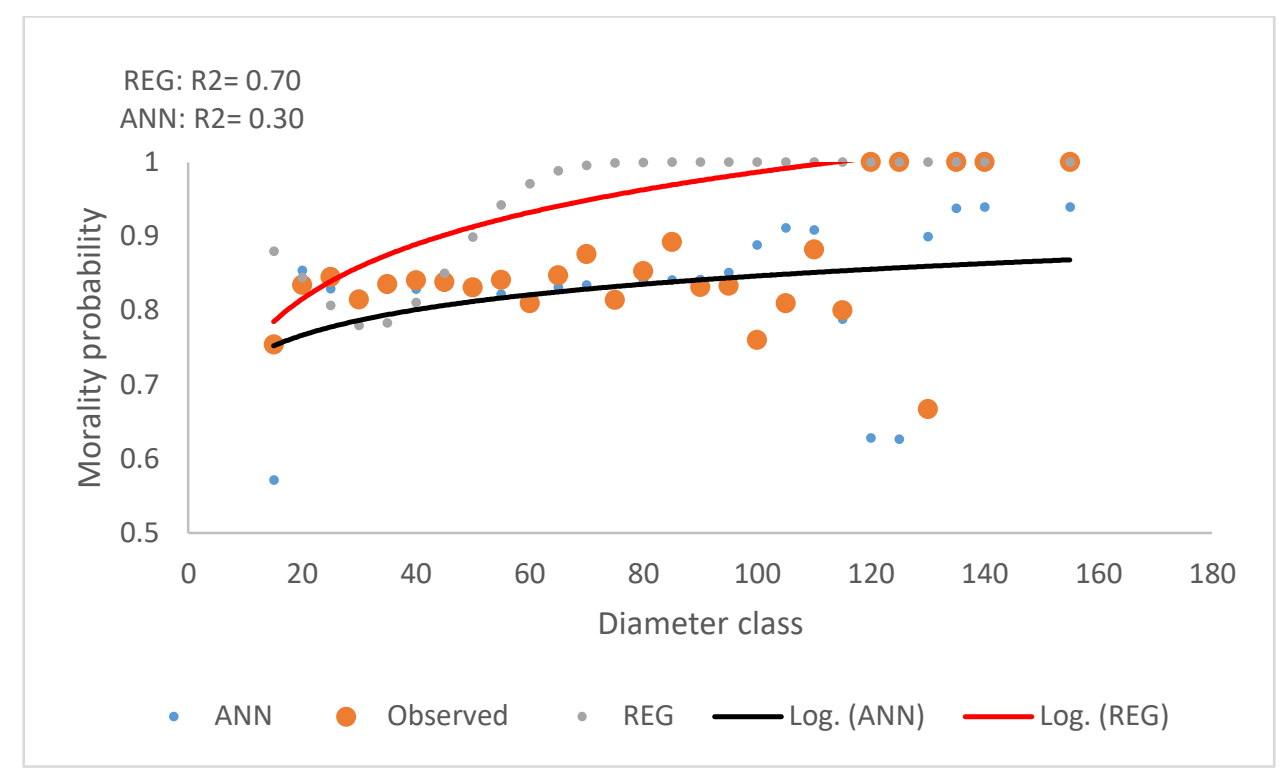

Figure 4. Model of survival by the parametric (mixed-effect regression (red line)) and non-

Evaluation results of survival model are given in Table 6, which suggest that the ANN were

Table 6. Evaluation results of survival model by modeling approach.

\begin{tabular}{ccc}
\hline Test & Mixed-effects & ANN \\
\hline Chi-Square value & 2862 & 5882 \\
\hline Hosmer \& Lemeshow Chi-square test & 0.070 & 0.092 \\
\hline ROC & 0.54 & 0.81 \\
\hline
\end{tabular}




\begin{tabular}{ccc}
\hline Nagelkerke R & 0.40 \\
\hline Cox \& Snell R & 0.43 & 0.37 \\
\hline
\end{tabular}

\section{Ingrowth model}

The average rate of ingrowth (number of trees that passed the diameter threshold of

$12.5 \mathrm{~cm}$ ) over a 10-year period was $42.8 \pm 6.4$ (mean $\pm \mathrm{SD}$ ) trees per ha, which was

unequally distributed among the different species (Table 7). The average diameter of

ingrowth trees in the 10-year period was $17.1 \pm 2.21 \mathrm{~cm}$. Equation 11 shows the ingrowth model:

$\ln (\mathrm{IN})=10.70-0.35(\mathrm{mDBH})+0.47(\mathrm{BA})-0.0043\left(\mathrm{BA}^{2}\right)$

$+0.01\left(\mathrm{BA}_{\text {Fagus }}\right)$

Equation 11

Where IN is the ingrowth of a 10-year period (number of trees that passed the diameter class of $12.5 \mathrm{~cm}) \mathrm{mDBH}$ is the stand-level mean diameter at breast height $(\mathrm{cm}), \mathrm{BA}$ is the total 364 basal area $\left(\mathrm{m}^{2} \mathrm{ha}^{-1}\right), \mathrm{BA}^{2}$ is the squared basal area $\left(\mathrm{m}^{2} \mathrm{ha}^{-1}\right)$ of each plot, and $\mathrm{BA}_{\text {Fagus }}$ is the 365 basal area $\left(\mathrm{m}^{2} \mathrm{ha}^{-1}\right)$ of Fagus species.

Table 7. Average number of trees passed the diameter threshold of $12.5 \mathrm{~cm}$ over a 10 -year period

\begin{tabular}{ccc}
\hline Species & $\begin{array}{r}\text { Number of trees per ha that exceed the diameter } \\
\text { threshold of } 12.5 \mathrm{~cm}\end{array}$ & $\begin{array}{c}\text { Maximum number of } \\
\text { trees per ha }\end{array}$ \\
\hline Beech & 21.21 & 110 \\
Hornbeam & 7.76 & 60 \\
Oak & 3.09 & 40 \\
Alder & 3.19 & 70 \\
Maple & 2.17 & 40 \\
Other Species & 5.36 & 60 \\
Total & 42.81 & 380 \\
\hline
\end{tabular}


The results of the ANN show that the MLP-based network of ingrowth had an RMSE of

0.54 trees per ha, a bias of 0.027 trees per ha, and performed better than RBF-based network

(Tables 8; Fig 5). In Table 8, only the models with high accuracy are given, while the

performance of all determined ANNs are provided in the Supplemental Materials (Table S7

and S8). However, predictions of ingrowth using both ANN and mixed-effects were

relatively similar across a range of basal areas (Figure 5).

Table 8. Characteristics of the superior MLP-based ANNs for the number of ingrowth trees per ha that

\begin{tabular}{cccccccccc}
\hline Sample & Structure & Algorithm & $\begin{array}{c}\text { Error } \\
\text { Function }\end{array}$ & $\begin{array}{c}\text { Hidden } \\
\text { activation }\end{array}$ & $\mathbf{R}^{\mathbf{2}}$ & RMSE & \%RMSE & BIAS & \%BIAS \\
\hline Train & MLP 10-5-1 & BFGS 95 & SOS & Logistic & 0.99 & 0.55 & 1.3 & 0.029 & 0.061 \\
\hline Test & MLP 10-5-1 & BFGS 95 & SOS & Logistic & 0.99 & 0.54 & 1.2 & 0.027 & 0.054 \\
\hline
\end{tabular}

MLP = multilayer perceptron (10-5-1 implies $10=$ number of input layers; $5=$ number of hidden layers; and $1=377$

number of output layer); RBF = radial basis function; BFGS = Broyden-Fletcher-Goldfarb-Shanno; RBFT = 378

Radial Basis Function Training; SOS = Symbiotic Organisms Search

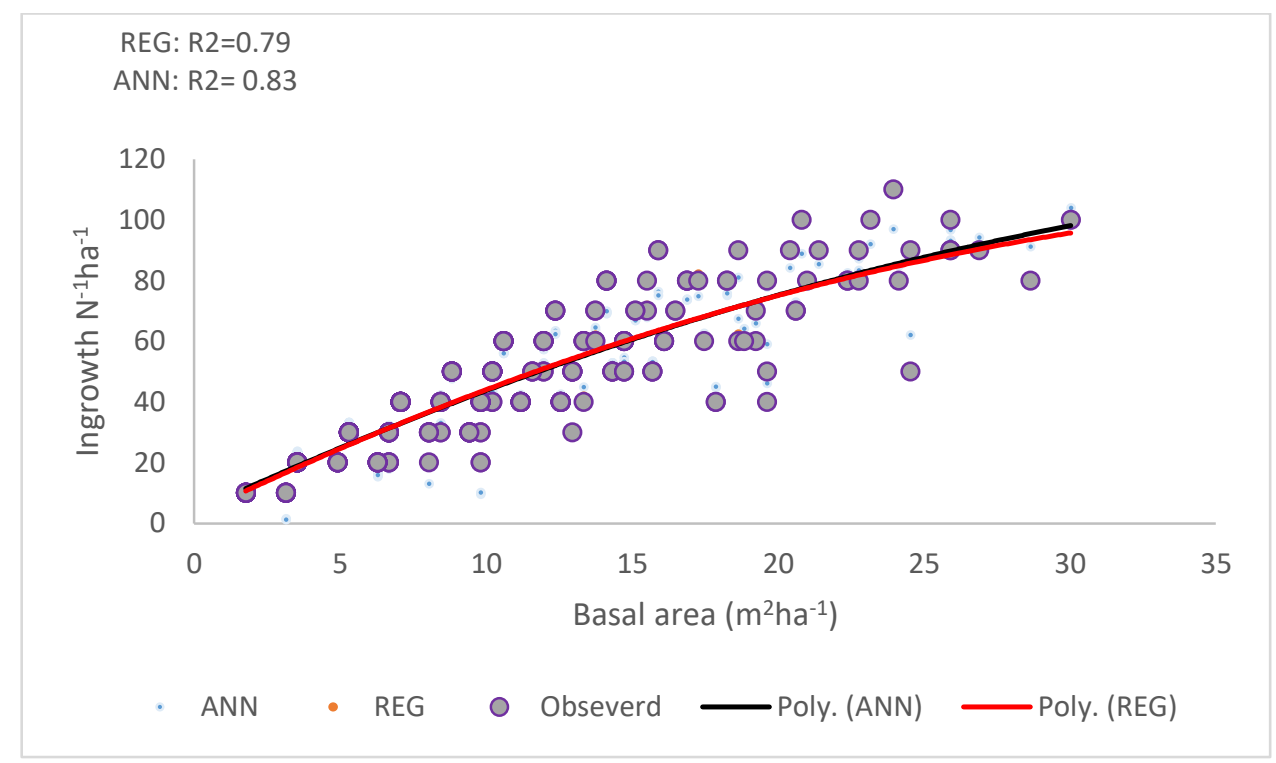

Figure 5. Predictions of the mixed-effects ingrowth model (Eqn. 11; number of trees passed the 
Comparison of modeling approach

A general comparison of the $\mathrm{R}^{2}$ and RMSEs from the parametric (mixed-effects) and

non-parametric (ANN) prediction methods indicated that the ANN resulted in the best

performance in this analysis (Table 9). For $\mathrm{R}^{2}$, the $\%$ improvement by ANN ranged from 3.1

to $157.1 \%$, while \% improvement for RMSE was between 10.0 and $94.9 \%$. The largest

improvements were primarily observed for the diameter increment model. However, as noted

above, many of the predictions using either ANN and mixed-effects were generally consistent

across the range of the data and both well aligned with observed trends.

Table 9. Comparison of various model fit statistics for parametric (mixed-effect regression)

and non-parametric methods (ANN) by equation.

\begin{tabular}{|c|c|c|c|c|c|c|c|c|c|}
\hline \multirow{2}{*}{ Model } & \multicolumn{3}{|c|}{ Parametric } & \multicolumn{3}{c|}{ Non-parametric } & \multicolumn{3}{c|}{ \% Improvement } \\
\cline { 2 - 11 } & $\mathrm{R}^{2}$ & RMSE & BIAS & $\mathrm{R}^{2}$ & RMSE & BIAS & $\mathrm{R}^{2}$ & RMSE & BIAS \\
\hline Diameter increment & 0.20 & 0.11 & 0.12 & 0.53 & 0.079 & 0.06 & 165.0 & -28.2 & -50.0 \\
\hline Height & 0.73 & 4.91 & 0.15 & 0.86 & 2.86 & 0.09 & 17.8 & -41.8 & -40.0 \\
\hline Survival & 0.24 & 0.38 & 0.043 & 0.36 & 0.28 & 0.011 & 50.0 & -26.3 & -74.4 \\
\hline Ingrowth & 0.96 & 0.60 & 2.17 & 0.99 & 0.54 & 1.2 & 3.1 & -10.0 & -44.7 \\
\hline
\end{tabular}

Discussion

Evaluation of the structure and dynamics of natural forests helps to determine the possibility of optimal forest management in achieving a desirable structure so that the implementation of appropriate silviculture operations in the stands under management can help to preserve the biological diversity and sustainability of forests (Ashraf et al, 2013, Zhao 401 et al., 2019). Forest structure and composition are very imperative factors for assessing forest 402 health and sustainability. Hyrcanian forests also have a variety of functions that require an 403 integrated and comprehensive management such as wood production, biodiversity, aesthetics, 
recreation and habitat. It appears that uneven-aged and mixed species management is an

efficient and efficacious way of attaining these varying goals (Bourque and Bayat. 2015,

Yang et al., 2019). However, lack of suitable decision-support tools for the proper

implementation of uneven management in mixed broad-leaved forests has delayed the scientific and efficient implementation of this technique (Bourque et al, 2019).

In this study, some models have been presented that can be employed in forest management. The models for uneven-aged, mixed forest presented in this study include

individual tree diameter growth, height, and survival (mortality) as well as ingrowth.

According to the results, the individual tree diameter growth had a robust performance across

the species examined (Equation 8). Results of a sensitivity analysis indicated that the most important independent variables used in the best model for diameter growth was the logarithm of DBH. Stand basal area and BAL were used to account for competition. BAL is the most common tool for quantifying one-sided competition because it is an absolute value, a simple calculation, and correlates well with the growth rate (Vanclay, 1994, Weiskittel, 2011, Kweon \& Comeau, 2019, Kuehne et al, 2020).

Results also showed that increased competition greatly reduced diameter growth across the species examined. In addition, the ANN based on the Multilayer Perceptron network (MLP) provided a better fit to the data than the RBF-based ANN (Tab 2, fig 3). The 422 results of the ANN sensitivity analysis showed in both cases that DBH and stand basal area 423 were the most influential variables whose effects were further modified by physiographic factors in the form of altitude, slope, and aspect. The parametric model for diameter growth indicated that highest growth was observed on northwest aspects $\left(300-340^{\circ}\right)$, but declined as the slope steepened. Weiskittel et al. (2007) found a similar influence of altitude, slope, and aspect on individual tree diameter growth of species in the US Pacific Northwest. 
In this study, the static technique was employed for modeling height growth. The descriptive statistics of trees' DBH and height indicated that observations were selected from a wide range of values (12.5 - $138 \mathrm{~cm}$ for $\mathrm{DBH}$ and $8.0-40.5 \mathrm{~m}$ for height; Table 3$)$. This suggests that nearly the full range of tree diameter and height for this area were considered. In the height model, species had no effect on the model, which was obtained when the model was fitted for all species separately and the difference was not statistically significant. The developed mixed effect regression height models from our work expressed tree height as a function of DBH and the best model we produced resulted in a RMSE value equal to $18.5 \%$, which was noticeably lower in the present study than reported by Trasobares et al. (2004), where it ranged from 21 to $24 \%$. This high accuracy is important as height models are needed for predicting tree volume. For the ANN method, the $\mathrm{R}^{2}$ and RMSE \% values were lower than the parametric method, which were 0.79 and $18.2 \%$, respectively. The MLP network had higher accuracy than RBF network. In addition, the important variable in this model included diameter, basal area, and basal area in larger trees.

The mortality of individual trees is an important event in the development of a forest stand and has significant applications in forest growth and product modeling (Bourque et al, 2019). In determining the survival model (mortality), despite the predictive difficulties of mortality at the stand level, there are many equations for estimating it at the tree level, and the logistic regression was used in this study similar to several previous studies (e.g. Hann et al., 2003; Monserud and Sterba, 1999). Guan and Gertner (1991) in their assessment of using ANN and the logistic function showed the former was an effective technique for tree mortality modeling, which other studies have also found (King et al, 2000; Metcalf et al., 450 2009). However, when the model is used on independent data, the difference between logistic regression and other fitting methods may be less obvious. As a result, logistic regression is 
generally appropriate due to its simplicity, robustness, and easy application for many practical purposes of mortality modeling (Yagi \& Primicerio, 2014).

Results of the developed survival model showed that trees with a diameter of 20 to 150

cm had the highest survival (Fig. 6). With an increase in competition (BAL), tree survival rate decreased rapidly. According to the analysis, beech trees also had a lower survival probability than others. Assessment and validation of tree mortality models was difficult because of its discontinuous and discrete nature (Han et al., 2006). According to our results, ANN was able to better estimate survival probability and to identify the predictors that contribute the most. ANN uses non-linear network connections and allows an analysis that 461 explores the efficacy of all input variables at the same time, which may lead to an improved 462 quality of the results. In this study, the validation of models was determined using 463 Nagelkerke $\mathrm{R}^{2}$ and its value was 0.40 (Table 6). According to studies, this parameter 464 represents a good fit of the model if the value is between 0.2 and 0.4 (Wilson et al., 2005). In 465 this study, the validity of the model was further assessed using Hosmer-Lemeshow test and 466 its value was 0.092 . Given the fact that the value of this parameter is greater than 0.05 , the 467 model obtained is valid (Pukkala and Kellomäki, 2012). In addition, the other criterion was 468 ROC, which was 0.81 and indicates relatively robust predictions. The correct prediction of 469 the survival model was $92 \%$ if 0.5 was used as a threshold for survival. In this model, the 470 diameter and basal area and their transformations were among the factors that had a high impact on the model, respectively, while the physiographic factors in this model had no effect.

Models of ingrowth predict the development of trees from the sapling stage instead of 474 predicting seedling development or trying to evaluate the variety of factors that influence the 475 process of forest stand rejuvenation (Ma et al., 2019). One of the benefits of this approach is 476 that the time needed for establishment of regeneration in the stand after the reduction of stand 
density due to harvesting allows it to be more realistic (Gould et al., 2006, 2007). Regarding

the results, the ingrowth model was generally reasonable and was more reliable than other

models (Fig. 8). The ANN showed that MLP approach had highest accuracy and lowest bias

(Table 8). Ingrowth increased with the basal area of stand, which is a similar finding to

results of Trasobares et al., (2004) who showed that the basal area had a major role in regeneration modeling. In this study, the ANN trial and error procedure showed that, depending on the input variables, four to ten hidden layers resulted in the best performance.

However, the number of neurons on the hidden layer varied based on the number of input

variables. Some researchers have suggested that the number of neurons on the hidden layer

should be more than twice that of the input neurons (Liu et al. 2013; Zhu et al. 2018).

Although other researchers found that, the number of hidden layers and their neurons is totally dependent on the size of the data, which always leads to a trial and error procedure or application of optimization techniques (Karaboga and Kaya, 2018).

Considering the potential of ANN in forest measurements and modeling, studies like Vendruscolo et al. (2017), Çatal and Saplioğlu (2018), Reis et al. (2018a, 2018b), Sanquetta 492 et al. (2018) and Vieira et al. (2018) have found that they generally perform better than 493 regression models, while they can be estimated with higher speeds and result in more precise 494 models. Thereby, in order to minimize the errors in growth models estimation in uneven-aged 495 forest, such as the Hyrcanian forest, the use of artificial intelligence techniques is very 496 important, (Aertsen et al., 2010; Breiman, 2001; Kano et al., 2017; Gorgens et al., 2015; Ozçelik et al.,2013, 2010; Reis et al., 2018; Siminsky, 2017; Simões and Shaw, 2007). In 498 particular, ANNs represent powerful methods for data analysis that can enhance estimation 499 skill (Xu et al., 2014). However, it is important to recognize many potential limitations of 500 non-parametric methods like ANN as they may overfit the data, cannot extrapolate beyond 501 the available training data, and do not guarantee biologically plausible behavior. 502 
Consequently, the assessment and evaluation of long-term growth projections from both

like $\mathrm{R}^{2}$ and RMSE does not necessitate better long-term (25+ years) growth projections (e.g.

Russell et al. 2011), which underscores the need and importance of robust model forms that

\section{Conclusion}

Today, a logical solution cannot be achieved in many planning and policy formulation

processes without modeling and simulation. Consequently, this study was aimed at providing

a growth model for the primary species in the Hyrcanian forest in order to determine the best

condition and the most important factors for their growth that can be used in forest

management. In this study, tree-level diameter growth, height, and survival as well as stand-

level ingrowth were developed using mixed effects and artificial neural networks. Individual

tree growth models are needed in order to determined suitable management regimes for the

uneven- aged and mixed Hyrcanian forests. Results showed the MLP model was more

According to the general findings, ANNs were capable of accurately and robustly 
ANN can likely be considered a very promising alternative technique when sufficient data is

available for analysis. Suggestions for future studies include applying ANN to other forest

regions and using other types of ANN to maximize the accuracies involved. In addition, it is

important to compare long-term projections using ANNs with actual field data to ensure

robust model behavior and performance that is well aligned with biological expectations.

Ultimately, the best approach for growth and yield modeling might be the hybridization of

Abbreviations

AI: Artificial intelligence;

ANN: Artificial Neural network;

$\mathrm{b}_{0}-\mathrm{b}_{\mathrm{n}}$ : parameters to be estimated;

BA: Basal area;

BAL: basal area in larger trees;

DBH: diameter at breast height;

GLM: Generalized linear model

m: meter

MLP: multilayer perceptron;

$\mathrm{P}_{\mathrm{i}}$ : the possibility of tree mortality for threshold $\mathrm{i}$;

RBF: Radial basis function;

RMSE: root mean squared error;

$\mathrm{X}_{(1)}-\mathrm{X}_{(\mathrm{n})}$ : descriptive variables; 
The datasets used and/or analyzed during the current study are available from the 553 corresponding author on reasonable requests.

\section{References}

1. Adame, P., Hynynen, J., Cañellas, I., del Río, M. 2008. Individual-tree diameter growth 556 model for rebollo oak (Quercus pyrenaica Willd.) coppices. Forest Ecology Management, 255: 1011-1022.

2. Aertsen, W., Kint, V., Van Orshoven, J., Özkan, K., \& Muys, B. 2010. Comparison and 559 ranking of different modelling techniques for prediction of site index in Mediterranean 560 mountain forests. Ecological Modelling, 221(8), 1119-1130.

3. Ahmadi, K., S.J. Alavi. 2016. Generalized height-diameter models for Fagus orientalis 562 Lipsky in Hyrcanian forest, Iran. Journal of Forest Science, 62 (9): 413-421.

4. Ahmadi, K., S.J. Alavi, G. Zahedi Amiri, S.M. Hosseini, M.J. Serra-Diaz, J.Ch. 564 Svenning. 2020. Patterns of density and structure of natural populations of Taxus baccata 565 in the Hyrcanian forests of Iran. Nordic Journal of Botany, 38 (3).

5. Ashraf, M. I., Zhao, Z., Bourque, C. P. A., MacLean, D. A., Meng, F. R. 2013. 567 Integrating biophysical controls in forest growth and yield predictions with artificial 568 intelligence technology. Canadian Journal of forest Research, 43(12): 1162-1171.

6. Bayat, M., Pukkala, T., Namiranian, M., Zobeiri, M. 2013. Productivity and optimal 570 management of the uneven-aged hardwood forests of Hyrcania. European Journal of 571 Forest Research, 132(5-6): 851-864.

7. Bayat, M., Namiranian, M., Zobeiri, M., Omid, M., Pukkala, T. 2014. Growth and yield models for uneven-aged and mixed broadleaf forest (Case study: Gorazbon District in 574 Kheyroud Forest, North of Iran). Iranian Journal of Forest and Poplar Research, 22(1): 575 39-50. 
8. Bayat, M., Ghorbanpour, M., Zare, R., Jaafari, A., Pham, B.T. 2019a. Application of artificial neural networks for predicting tree survival and mortality in the Hyrcanian forest of Iran. Computers and Electronics in Agriculture, 164: 104929

9. Bayat, M.; Noi, P.T; Zare, R.; Bui, D.T. 2019b. A semi-empirical approach based on 580 genetic programming for the study of biophysical controls on diameter-growth of Fagus orientalis in Northern Iran. Remote Sensing, 11: 1680.

10. Bayat, M.; Bettinger, P.; Heidari, S.; Henareh Khalyani, A.; Jourgholami, M.; Hamidi, 583 S.K. 2020. Estimation of tree heights in an uneven-aged, mixed forest in northern Iran 584 using artificial intelligence and empirical models. Forests, 11: 324.

11. Baskent, E.Z., Keles, S. 2005. Spatial forest planning: A review. Ecological Modeling, 586 188: $145-173$.

12. Bettinger, P., Gratez, D., Sessions, J. 2005. A density-dependent stand-level optimization 588 approach for deriving management prescriptions for Interior Northwest (USA) 589 landscapes. Forest Ecology and Management, 217(2-3): 171-186.

13. Bettinger, P., Merry, K., Bayat, M. and Tomaštík, J., 2019. GNSS use in forestry-A 591 multi-national survey from Iran, Slovakia and southern USA. Computers and Electronics in Agriculture, 158: 369-383.

14. Burkhart, H. E. 1990. Status and future of growth and yield models. In: Proc. of a Symp. 594 on state-of the methodology of forest inventory. USDA For. Serv., PNW GTR 283: 409595 414.

15. Benali, L., Notton, G., Fouilloy, A., Voyant, C., Dizene, R. 2019. Solar radiation 597 forecasting using artificial neural network and random forest methods: Application to 598 normal beam, horizontal diffuse and global components. Renewable Energy, 132: 871599 884. 
16. Bourque, C.P.A.; Bayat, M. 2015. Landscape variation in tree species richness in 601 Northern Iran Forests. PLOS ONE, 10(4): e0121172. 602

17. Bourque, C.P.A.; Bayat, M.; Zhang, C. 2019. An assessment of height-diameter growth 603 variation in an unmanaged Fagus orientalis -dominated forest. European Journal of 604 $\begin{array}{ll}\text { Forest Research, 138(4): 607-621. } & 605\end{array}$

18. Çatal, Y.; Saplioğlu, K. 2018. Comparison of adaptive neuro-fuzzy inference system, 606 artificial neural networks and non-linear regression for bark volume estimation in 607 Brutian pine (Pinus brutia ten.). Applied Ecology and Environmental Research, 16(2): 608 2015-2027.

19. Cañadas-L, Á. Andrade-Candell, J., Manuel Domínguez-A, J., Molina-H, C., Schnabel- 610 D, O, Vargas-Hernández, J., Wehenkel, Ch. 2018. Growth and yield models for teak 611 planted as living fences in coastal Ecuador. Forests 9, $55 . \quad 612$

20. Da Rocha, S.J.S.S., Torres, C.M.M.E., Jacovine, L.A.G., Leite, H.G., Gelcer, E.M., 613 Neves, K.M., Zanuncio, J.C. 2018. Artificial neural networks: Modeling tree survival 614 and mortality in the Atlantic Forest biome in Brazil. Science of the Total Environment, 615 645: $655-661 . \quad 616$

21. Eerikainen, K., Valkonen, S., Saksa, T. 2014. Ingrowth, survival and height growth of 617 small trees in uneven-aged Picea abies stands in southern Finland. Forest Ecosystems, 1: $\quad 618$

5.

22. Eslami, A. 2017. Determination the structure of oriental beech, Fagus orientalis Lipsky 620 stands (Case study: Asalem watershed forests, north of Iran). Caspian J. Environ. Sci., 15(1): 57-66.

23. Flewelling, J.W., de Jong. R. 1994. Considerations in simultaneous curve fitting for 623 repeated height-diameter measurements. Canadian Journal of Forest Research, 24: 14081414. 
24. Gould, P.J., Steiner, K.C., Mcdill, M. E., Finley, J.C. 2006. Modeling seed-origin oak regeneration in the central Appalachians. Canadian Journal of Forest Research, 36: 833844.

25. Gould, P.J., Fei, S., Steiner, K.C. 2007. Modeling sprout-origin oak regeneration in the central Appalachians, Canadian Journal of Forest Research, 37: 170-177.

26. Guan, B.T., Gertner, G., 1991. Modeling red pine tree survival with an artificial neural network. Forest Science, 37: 1429-1440.

27. Hamidi, K., Fallah, A. Bayat, $M$ and Hosseini yekani. S.A. 2019. Investigating the diameter and height models of beech trees in uneven age forest of northern Iran (Case study: Forest Farim), Iranian Forest Ecology, 3 (11): 373-386.

28. Hann, D.W., Marshall, D.D. Hanus, M.L. 2003. Equation for predicting height- tocrown base, 5-year diameter growth rate, 5-year height growth rate, 5-year mortality rate, 637 and maximum size-density trajectory for Douglas-fir and western hemlock in the coastal region of the Pacific Northwest. Research Contribution 40, Oregon State University, College of Forestry Research Laboratory, Corvallis, OR, 85p.

29. Hann, D.W., Marshall, D.D., Hanus, M.L. 2006. Reanalysis of the SMC-ORGANON equations for diameter-growth rate, height -growth rate, and mortality rate of Douglas642 fir. Research Contribution 49. Oregon State University, Forest Research Laboratory, Corvallis, OR.

30. Hatfield, J., Prueger, J. 2015. Temperature extremes: Effect on plant growth and development. Weather and Climate Extremes, 10: 4-10.

31. Härkönen, S., Mäkinen, A., Tokola, T., Rasinmäki, J., Kalliovirta, J. 2010. Evaluation of 
32. Ingram, J. C., Dawson, T. P., Whittaker, R. J. 2005. Mapping tropical forest structure in southeastern Madagascar using remote sensing and artificial neural networks. Remote Sensing of Environment, 94(4): 491-507.

33. Kalbi, S., Fallah, A., Shataee, Sh., Bettinger, P., Yousefpour, R. 2019. Growth and yield models for uneven-aged forest stands managed under a selection system in northern Iran, Eurasian Journal of Forest Science, 7(3): 321-333.

34. King, S.L., BENNETT, K. P. LIST, S. 2000. Modeling catastrophic individual tree 656 morality using logistic regression, neural network and Support Vector Machine. 657 Computer and Electronics in Agriculture, 27: 401 - 406.

35. Kuehne, C., Russell, M.B., Weiskittel, A.R., Kershaw Jr, J.A. 2020. Comparing 659 strategies for representing individual-tree secondary growth in mixed-species stands in 660 the Acadian Forest region. Forest Ecology and Management 459: 117823.

36. Kweon, D., Comeau, P.G. 2019. Relationships between tree survival, stand structure and 662 age in trembling aspen dominated stands. Forest Ecology and Management, 438: 114663 122.

37. Janizadeh, S., Avand, M., Jaafari, A., Phong, T.V., Bayat, M., Ahmadisharaf, E., 665 Prakash, I., Pham, B.T. and Lee, S., 2019. Prediction success of machine learning 666 methods for flash flood susceptibility mapping in the Tafresh Watershed, Iran. 667 $\begin{array}{ll}\text { Sustainability, } 11(19): 5426 . & 668\end{array}$

38. Lei, Y.C., Zhang, S.Y. 2004. Feature and partial derivatives of Bertalanffy-Richards 669 growth model in forestry. Nonlinear Analysis: Modeling and Control, 9(1): 65-73.

39. Li, R., Weiskittel, A.R., Kershaw Jr, J.A. 2011. Modeling annualized occurrence, 671 frequency, and composition of ingrowth using mixed-effects zero-inflated models and permanent plots in the Acadian Forest Region of North America, Canadian Journal of 673 Forest Research, 41(10): 2077-2089. 
40. Ling, J. 2010. Dynamics and management of Alaska boreal forest: an all aged multi- 675 species matrix growth model. Forest Ecology and Management, 260: 491-501. 676

41. Ma, P., Hana, X., Lina, Y., Moore, J., Guo, Y., Yue, M. 2019. Exploring the relative 677 importance of biotic and abiotic factors that alter the self-thinning rule: Insights from 678 individual-based modelling and machine learning. Ecological Modelling, 397: 16-24. 679

42. Mehtätalo, L., Lappi, J. 2020. Biometry for Forestry and Environmental Data 680 with Examples in R. Publisher Taylor \& Francis Inc, 412p.

43. Metcalf, C., James, E. Clark, S. and Clark, A. 2009. Tree growth inference and 682 prediction when the point of measurement changes: Modelling around buttresses in 683 tropical forests. Journal of Tropical Ecology, 25: 1-12.

44. Monserud, R.A., Sterba, H. 1999. Modeling individual tree mortality for Austrian forest 685 species. Forest Ecology and Management, 113: 109-123.

45. Nagy, H.M., Watanabe, K., Hirano, M., 2002. Prediction of sediment load concentration 687 in rivers using artificial neural network model. Journal of Hydraulic Engineering, 128: 688 $588-595$.

46. Nandy, S., Singh, R., Ghosh, S., Watham, T., Kushwaha, S.P.S., Kumar, A.S., Dadhwal, 690 V.K. 2017. Neural network-based modelling for forest biomass assessment. Carbon 691 Management, 8(4): 305-317.

47. Ozçelik, R., Diamantopoulou, J.M., Brooks, J.R., and Wiant, H.V., 2010. Estimating tree 693 bole volume using artificial neural network models for four species in Turkey. Journal of 694 Environmental Management 91: 742-753.

48. Özçelik, R., Diamantopoulou, M.J., Crecente-Campo, F., Eler, F. 2013. Estimating 696 Crimean juniper tree height using nonlinear regression and artificial neural network 697 models. Forest Ecology and Management, 306: 52-60. 
49. Silva, J.P.M., da Silva, M.L.M., da Silva, E.F., da Silva, G.F., de Mendonça, A.R.,

Cabacinha, C.D., Araújo, E.F., Santos, J.S., Vieira, G.C., de Almeida, M.N.F., and de

Moura Fernandes, M.R. 2019. Computational techniques applied to volume and biomass

estimation of trees in Brazilian savanna. Journal of Environmental Management, 249(1):

702

109368.

50. Pinheiro J, Bates D, DebRoy S, Sarkar D, and R Core Team. 2020. nlme: Linear and 704 Nonlinear Mixed Effects Models. R package version 3.1-148, https://CRAN.R705 project.org/package=nlme. 706

51. Pukkala, T., Lähde, E., Laiho, O. 2009. Growth and yield models for uneven aged stand 707 in Finland. Forest Ecology and Management, 258: 207-216.

52. Pukkala, T., Kellomäki S. 2012. Anticipatory vs. adaptive optimization of stand 709 management when tree growth and timber prices are stochastic. Forestry, 85(4): 463710 472.

53. Reis, L.P., de Souza, A.L., dos Reis, P.C.M., Mazzei, L., Soares, C.P.B., Torres, 712 C.M.M.E., da Silva, L.F., Ruschel, A.R., Rêgo, L.J.S. and Leite, H.G. 2018. Estimation 713 of mortality and survival of individual trees after harvesting wood using artificial neural 714 networks in the Amazon rain forest. Ecological Engineering, 112, 140-147.

54. Russell, M.B., Weiskittel, A.R., Kershaw, J.A. 2011. Assessing model performance in 716 forecasting long-term individual tree diameter versus basal area increment for the primary Acadian species. Canadian Journal of Forest Research 41, 2267-2275.

55. Sáncheza, C.A.L., Varela, J.G., Doradoa, F.C., Alboreca, A.R., Soalleiro, R.R., 719 Gonzalez, J.G.A. Rodriguez, F.S. 2003. A height-diameter model for Pinus radiata D. 720 Don in Galicia (North-west Spain), Annals of Forest Science, 60: 237-245.

56. Schumacher, F.X. 1939. A new growth curve and its application to timber yield studies. 722 Journal of Forestry, 37: 819 -820. 
57. Sharma, M., Zhang, S.Y. 2004. Height-diameter models using stand characteristics for

Pinus banksiana and Picea mariana, Scandinavian Journal of Forest Research, 19: 442451.

58. Sirkia, S., Heinonen, J., Miina, J., Eerikainen. K. 2014. Subject-specific prediction using 727 a nonlinear mixed model: consequences of different approaches. Forest Science, 61(2): 728 205-212.

59. Stonkova, T.V. 2016. A dynamic whole-stand growth model, derived from allometric 730 relationships. Silva Fennica, 50: 1406.

60. Strobl1, R.O., and Forte, F. 2007. Artificial neural network exploration of the influential 732 factors in drainage network derivation. Hydrological Processes, 21: 2965-2978.

61. Trasobares, A., Pukkala, T. 2004. Using past growth to improve individual-tree diameter 734 growth models for uneven-aged mixtures Pinus sylvestris L. and Pinus nigra Arn. in 735 Catalonia, north-east Spain, Annals of Forest Science, 61: 409-417.

62. Uzoh F.C.C., Oliver, W.W. 2008. Individual tree diameter increment model for 737 managed even-aged stands of ponderosa pine throughout the western United States 738 using a multilevel linear mixed effects model. Forest Ecology Management, 256: 438445.

63. Vanclay, J.K. 1991.Aggregating tree species to develop diameter increment equations for 741 tropical rain forests. Forest Ecology and Management, 42: 143-168.

64. Vanclay, J.K. 1994. Modelling forest growth and yield: application to mixed tropical 743 forests. CAB international, 330p.

65. Vendruscolo, D.G.S., Chaves, A.G.S., Medeiros, R.A., Da Silva, R.S., Souza, H.S., 745 Drescher, R., Leite, H.G. 2017. Height estimative of Tectona grandis L. f. trees using 746 regression and artificial neural networks. Nativa: Pesquisas Agrárias e Ambientais, 5(1): $52-58$. 
66. Vieira, G. C., de Mendonça, A. R., da Silva, G. F., Zanetti, S. S., da Silva, M. M., \& dos

Santos, A.R. 2018. Prognoses of diameter and height of trees of eucalyptus using 750 artificial intelligence. Science of the Total Environment, 619: 1473-1481.

67. Van Dao, D., Jaafari, A., Bayat, M., Mafi-Gholami, D., Qi, C., Moayedi, H., Van Phong, 752 T., Ly, H.B., Le, T.T., Trinh, P.T. and Luu, C., 2020. A spatially explicit deep learning 753 neural network model for the prediction of landslide susceptibility. Catena, 188: 104451. 754

68. Weiskittel, A.R., Garber, S.M., Johnson, G.P., Maguire, D.A., and Monserud, R.A., 755 2007. Annualized diameter and height growth equations for Pacific Northwest 756 plantation-grown Douglas-fir, western hemlock, and red alder. For. Ecol. Manage. 250: $266-278$.

69. Weiskittel, A.R., Hann, D.W., Kershaw Jr, J.A. and Vanclay, J.K., 2011. Forest growth 759 and yield modeling. John Wiley \& Sons.

70. Xu, H., Sun, Y., Wang, X., Li, Y. 2014. Height-diameter models of Chinese fir 761 (Cunninghamia lanceolata) based on nonlinear mixed-effects models in Southeast China. 762 Advance Journal Food Science Technology, 6(4): 445-452

71. Yang M, Cai T, Ju C, et al. 2019. Evaluating spatial structure of a mixed broad764 leaved/Korean pine forest based on neighborhood relationships in Mudanfeng National 765 Nature Reserve, ChinaJournal of Forestry Research, , 30(4): 1375-1381.

72. Yagi, A., Primicerio M. 2014. A modified forest kinematic model, Vietnam Journal of 767 Mathematical Applications, 12: 107-118.

73. Zhao, J., He, C., Qi, C. et al. Biomass increment and mortality losses in tropical 769 secondary forests of Hainan, China. J. For. Res. 30, 647-655 (2019). 770 https://doi.org/10.1007/s11676-018-0624-7 
74. Zhou, R.; Wu, D.; Zhou, R.; Fang, L.; Zheng, X.; Lou, X. 2019. Estimation of DBH at 772 forest stand level based on multi-parameters and generalized regression neural network. 773

$\begin{array}{ll}\text { Forests, 10: } 778 . & 774\end{array}$

75. Zhu, X.X., Zhou, L.Y., 2007. Suspended sediment flux modeling with artificial neural 775 network: An example of the Longchuanjiang River in the Upper Yangtze Catchment, 776 China. Geomorphology, 84:111-125. 777

76. Zhu, A. X., Miao, Y., Wang, R., Zhu, T., Deng, Y., Liu, J. Hong, H. 2018. A 778 comparative study of an expert knowledge-based model and two data-driven models for 779 landslide susceptibility mapping. Catena, 166, 317-327. 780

$\begin{array}{ll}\text { Acknowledgements: } & 781\end{array}$

This study did not receive any specific grant from funding agencies in the public, 782 $\begin{array}{ll}\text { commercial, or not-for-profit sectors. } & 783\end{array}$

$\begin{array}{ll}\text { Author information } & 785\end{array}$

$\begin{array}{ll}\text { Affiliations } & 786\end{array}$

Sari Agriculture Sciences and Natural Resource University, Sari, Mazandaran, Iran 787

$\begin{array}{ll}\text { Seyedeh Kosar Hamidi \& Asghar Fallah } & 788\end{array}$

Center for Research on Sustainable Forests, University of Maine, Orono, ME, USA 789

$\begin{array}{ll}\text { Aaron Weiskittel } & 790\end{array}$

Research Institute of Forests and Rangelands, Agricultural Research, Education, and Extension 791

$\begin{array}{ll}\text { Organization (AREEO), Tehran, Iran. } & 792\end{array}$

$\begin{array}{ll}\text { Mahmoud Bayat } & 793\end{array}$

$\begin{array}{ll}\text { Author Contribution Statement } & 794\end{array}$

The concept of the paper was conceived by Seyedeh Kosar Hamidi. Field data were evenly 795 collected by Seyedeh Kosar Hamidi and Asghar Fallah. All authors had various roles in (i) 796 analyzing and formatting the data, and (ii) preparing and editing the manuscript. 797 
Ethics declarations

Ethics approval and consent to participate

Not applicable.

Not applicable.

\section{Competing interests}

804

The authors declare that they have no competing interests.

Supplemental Materials: Total computational tables by MLP and RBF-based methods

Table S1. Characteristics of RBF and MLP-based ANNs for individual tree diameter growth

in bold.

\begin{tabular}{cccccccccc}
\hline Index & Structure & Algorithm & $\begin{array}{c}\text { Error } \\
\text { Function }\end{array}$ & $\begin{array}{c}\text { Hidden } \\
\text { activation }\end{array}$ & $\mathbf{R}^{\mathbf{2}}$ & RMSE & \%RMSE & BIAS & \%BIAS \\
\hline $\mathbf{1}$ & MLP 13-6-1 & BFGS 57 & SOS & Tanh & $\mathbf{0 . 5 5}$ & $\mathbf{0 . 9 3}$ & $\mathbf{4 . 7 9}$ & $\mathbf{0 . 1 0}$ & $\mathbf{0 . 5 1}$ \\
\hline 2 & MLP 13-12-1 & BFGS 72 & SOS & Logistic & 0.53 & 0.97 & 5 & 0.12 & 0.61 \\
\hline 3 & MLP 13-11-1 & BFGS 55 & SOS & Tanh & 0.49 & 0.95 & 4.89 & 0.17 & 0.87 \\
\hline 4 & MLP 13-13-1 & BFGS 32 & SOS & Logistic & 0.54 & 0.98 & 5.05 & 0.12 & 0.61 \\
\hline 5 & MLP 13-7-1 & BFGS 27 & SOS & Exponential & 0.51 & 0.96 & 4.94 & 0.11 & 0.56 \\
\hline 6 & RBF 13-30-1 & RBFT & SOS & Gaussian & 0.36 & 2.76 & 14.22 & 0.43 & 2.21 \\
\hline 7 & RBF 13-26-1 & RBFT & SOS & Gaussian & 0.07 & 4.86 & 25.05 & 9.02 & 46.49 \\
\hline 8 & RBF 13-27-1 & RBFT & SOS & Gaussian & 0.05 & 4.81 & 24.79 & 8.18 & 42.16 \\
\hline 9 & RBF 13-31-1 & RBFT & SOS & Gaussian & 0.04 & 4.83 & 24.89 & 11.01 & 56.75 \\
\hline 10 & RBF 13-28-1 & RBFT & SOS & Gaussian & 0.39 & 2.14 & 11.03 & 0.87 & 4.48 \\
\hline
\end{tabular}

Table S2. Characteristics of RBF and MLP-based ANNs for individual tree diameter growth 


\begin{tabular}{ccccccccccc}
\hline Index & Structure & Algorithm & $\begin{array}{c}\text { Error } \\
\text { Function }\end{array}$ & $\begin{array}{c}\text { Hidden } \\
\text { activation }\end{array}$ & $\mathbf{R}^{\mathbf{2}}$ & RMSE & \% RMSE & BIAS & \%BIAS \\
\hline $\mathbf{1}$ & MLP 13-6-1 & BFGS 57 & SOS & Tanh & $\mathbf{0 . 5 3}$ & $\mathbf{0 . 7 9}$ & $\mathbf{3 . 9 8}$ & $\mathbf{0 . 0 6}$ & $\mathbf{0 . 3 0}$ \\
\hline 2 & MLP 13-12-1 & BFGS 72 & SOS & Logistic & 0.47 & 0.81 & 4.09 & 0.07 & 0.35 \\
\hline 3 & MLP 13-11-1 & BFGS 55 & SOS & Tanh & 0.51 & 0.97 & 4.89 & 0.09 & 0.45 \\
\hline 4 & MLP 13-13-1 & BFGS 32 & SOS & Logistic & 0.48 & 0.99 & 5 & 0.08 & 0.40 \\
\hline 5 & MLP 13-7-1 & BFGS 27 & SOS & Exponential & 0.48 & 0.86 & 4.34 & 0.08 & 0.40 \\
\hline 6 & RBF 13-30-1 & RBFT & SOS & Gaussian & 0.38 & 1.36 & 6.86 & 0.83 & 4.19 \\
\hline 7 & RBF 13-26-1 & RBFT & SOS & Gaussian & 0.05 & 2.64 & 13.33 & 1.46 & 7.37 \\
\hline 8 & RBF 13-27-1 & RBFT & SOS & Gaussian & 0.08 & 2.83 & 14.29 & 1.32 & 6.66 \\
\hline 9 & RBF 13-31-1 & RBFT & SOS & Gaussian & 0.06 & 2.56 & 12.92 & 1.41 & 7.12 \\
\hline 10 & RBF 13-28-1 & RBFT & SOS & Gaussian & 0.38 & 1.16 & 5.85 & 0.89 & 4.49 \\
\hline
\end{tabular}

Table S3. Characteristics of RBF and MLP-based ANNs for individual tree height and

bold.

\begin{tabular}{cccccccccc}
\hline Index & Structure & Algorithm & $\begin{array}{c}\text { Error } \\
\text { Function }\end{array}$ & $\begin{array}{c}\text { Hidden } \\
\text { activation }\end{array}$ & $\mathbf{R}^{2}$ & RMSE & \%RMSE & BIAS & \%BIAS \\
\hline 1 & MLP 3-3-1 & BFGS 14 & SOS & Identity & 0.74 & 4.90 & 18.59 & 0.0003 & 0.001 \\
\hline 2 & MLP 3-9-1 & BFGS 13 & SOS & Exponential & 0.74 & 4.90 & 18.55 & 0.026 & 0.1 \\
\hline $\mathbf{3}$ & MLP 3-4-1 & BFGS 15 & SOS & Identity & $\mathbf{0 . 7 4}$ & $\mathbf{4 . 8 9}$ & $\mathbf{1 8 . 5 3}$ & $\mathbf{0 . 0 0 0 3}$ & $\mathbf{0 . 0 0 1}$ \\
\hline 4 & MLP 3-5-1 & BFGS 10 & SOS & Identity & 0.74 & 4.91 & 18.59 & 0.001 & 0.007 \\
\hline 5 & MLP 3-10-1 & BFGS 14 & SOS & Exponential & 0.74 & 4.91 & 18.60 & 0.19 & 0.72 \\
\hline 6 & RBF 3-22-1 & RBFT & SOS & Gaussian & 0.28 & 26.27 & 99.50 & 3.99 & 15.11 \\
\hline 7 & RBF 3-23-1 & RBFT & SOS & Gaussian & 0.04 & 41.16 & 155.90 & 9.14 & 34.62 \\
\hline 8 & RBF 3-27-1 & RBFT & SOS & Gaussian & 0.02 & 57.59 & 218.14 & 12.23 & 46.32 \\
\hline 9 & RBF 3-29-1 & RBFT & SOS & Gaussian & 0.05 & 39.54 & 149.77 & 8.31 & 31.47 \\
\hline 10 & RBF 3-21-1 & RBFT & SOS & Gaussian & 0.16 & 36.52 & 138.33 & 5.14 & 19.46 \\
\hline
\end{tabular}

Table S4. Characteristics of RBF and MLP-based ANNs for individual tree height and

associated goodness-of-fit criteria for model evaluation. The superior model is shown in bold.

\begin{tabular}{cccccccccc}
\hline Index & Structure & $\begin{array}{c}\text { Algorith } \\
\mathbf{m}\end{array}$ & $\begin{array}{c}\text { Error } \\
\text { Functi } \\
\text { on }\end{array}$ & $\begin{array}{c}\text { Hidden } \\
\text { activation }\end{array}$ & $\mathbf{R}^{2}$ & RMSE & \%RMSE & BIAS & \%BIAS \\
\hline 1 & MLP 3-3-1 & BFGS 14 & SOS & Identity & 0.85 & 2.89 & 10.63 & 0.17 & 0.63 \\
\hline 2 & MLP 3-9-1 & BFGS 13 & SOS & Exponential & 0.86 & 2.86 & 10.54 & 0.17 & 0.63 \\
\hline $\mathbf{3}$ & MLP 3-4-1 & BFGS 15 & SOS & Identity & $\mathbf{0 . 8 6}$ & $\mathbf{2 . 8 6}$ & $\mathbf{1 0 . 5 5}$ & $\mathbf{0 . 0 9}$ & $\mathbf{0 . 3 4}$ \\
\hline
\end{tabular}




\begin{tabular}{cccccccccc}
\hline 4 & MLP 3-5-1 & BFGS 10 & SOS & Identity & 0.85 & 2.88 & 10.60 & 0.16 & 0.61 \\
\hline 5 & MLP 3-10-1 & BFGS 14 & SOS & Exponential & 0.85 & 2.89 & 10.64 & 0.18 & 0.67 \\
\hline 6 & RBF 3-22-1 & RBFT & SOS & Gaussian & 0.19 & 24.33 & 89.48 & 8.14 & 29.93 \\
\hline 7 & RBF 3-23-1 & RBFT & SOS & Gaussian & 0.12 & 36.67 & 134.86 & 10.23 & 37.62 \\
\hline 8 & RBF 3-27-1 & RBFT & SOS & Gaussian & 0.22 & 21.75 & 79.99 & 4.84 & 17.80 \\
\hline 9 & RBF 3-29-1 & RBFT & SOS & Gaussian & 0.22 & 21.73 & 79.91 & 4.65 & 17.10 \\
\hline 10 & RBF 3-21-1 & RBFT & SOS & Gaussian & 0.11 & 39.11 & 143.83 & 11.12 & 40.89 \\
\hline
\end{tabular}

Table S5. Characteristics of RBF and MLP-based ANNs for individual tree survival and

associated goodness-of-fit criteria for model train. The superior model is shown in bold.

\begin{tabular}{cccccccccc}
\hline Index & Structure & Algorithm & $\begin{array}{c}\text { Error } \\
\text { Function }\end{array}$ & $\begin{array}{c}\text { Hidden } \\
\text { activation }\end{array}$ & $\mathbf{R}^{\mathbf{2}}$ & RMSE & \%RMSE & BIAS & \%BIAS \\
\hline 1 & MLP 5-5-1 & $\begin{array}{c}\text { BFGS } \\
1000\end{array}$ & SOS & Exponential & 0.13 & 0.36 & 36.91 & 0.0014 & 0.11 \\
\hline 2 & MLP 5-11-1 & BFGS 46 & SOS & Logistic & 0.12 & 0.36 & 36.96 & 0.0012 & 0.12 \\
\hline $\mathbf{3}$ & MLP 5-7-1 & BFGS 132 & SOS & Logistic & $\mathbf{0 . 2 7}$ & $\mathbf{0 . 3 5}$ & $\mathbf{3 5 . 7 7}$ & $\mathbf{0 . 0 0 5}$ & $\mathbf{0 . 0 1}$ \\
\hline 4 & MLP 5-4-1 & BFGS 65 & SOS & Tanh & 0.16 & 0.36 & 36.70 & 0.008 & 0.14 \\
\hline 5 & MLP 5-7-1 & BFGS 188 & SOS & Logistic & 0.16 & 0.36 & 36.71 & 0.009 & 0.31 \\
\hline 6 & RBF 5-21-1 & RBFT & SOS & Gaussian & 0.08 & 0.43 & 43.71 & 0.0021 & 1.42 \\
\hline 7 & RBF 5-27-1 & RBFT & SOS & Gaussian & 0.11 & 0.38 & 38.74 & 0.0011 & 0.23 \\
\hline 8 & RBF 5-23-1 & RBFT & SOS & Gaussian & 0.12 & 0.36 & 36.72 & 0.0012 & 0.12 \\
\hline 9 & RBF 5-23-1 & RBFT & SOS & Gaussian & 0.10 & 0.39 & 39.23 & 0.009 & 1.09 \\
\hline 10 & RBF 5-22-1 & RBFT & SOS & Gaussian & 0.12 & 0.36 & 36.39 & 0.0012 & 0.14 \\
\hline
\end{tabular}

Table S6. Characteristics of RBF and MLP-based ANNs for individual tree survival and

\begin{tabular}{cccccccccc}
\hline Index & Structure & Algorithm & $\begin{array}{c}\text { Error } \\
\text { Function }\end{array}$ & $\begin{array}{c}\text { Hidden } \\
\text { activation }\end{array}$ & $\mathbf{R}^{\mathbf{2}}$ & RMSE & \%RMSE & BIAS & \%BIAS \\
\hline 1 & MLP 5-5-1 & $\begin{array}{c}\text { BFGS } \\
1000\end{array}$ & SOS & Exponential & 0.11 & 0.39 & 39.28 & 0.023 & 2.39 \\
\hline 2 & MLP 5-11-1 & BFGS 46 & SOS & Logistic & 0.09 & 0.39 & 39.35 & 0.023 & 2.32 \\
\hline $\mathbf{3}$ & MLP 5-7-1 & BFGS 132 & SOS & Logistic & $\mathbf{0 . 3 6}$ & $\mathbf{0 . 2 8}$ & $\mathbf{2 8 . 0 1}$ & $\mathbf{0 . 0 1 1}$ & $\mathbf{1 . 1 9}$ \\
\hline 4 & MLP 5-4-1 & BFGS 65 & SOS & Tanh & 0.13 & 0.39 & 39.21 & 0.020 & 2.09 \\
\hline 5 & MLP 5-7-1 & BFGS 188 & SOS & Logistic & 0.16 & 0.39 & 39.02 & 0.020 & 2.09 \\
\hline 6 & RBF 5-21-1 & RBFT & SOS & Gaussian & 0.10 & 0.41 & 41.71 & 0.025 & 2.56 \\
\hline 7 & RBF 5-27-1 & RBFT & SOS & Gaussian & 0.08 & 0.45 & 45.57 & 0.12 & 1.23 \\
\hline 8 & RBF 5-23-1 & RBFT & SOS & Gaussian & 0.04 & 0.76 & 76.98 & 0.23 & 2.34 \\
\hline 9 & RBF 5-23-1 & RBFT & SOS & Gaussian & 0.14 & 0.39 & 39.26 & 0.045 & 4.58 \\
\hline 10 & RBF 5-22-1 & RBFT & SOS & Gaussian & 0.17 & 0.40 & 40.11 & 0.043 & 4.37 \\
\hline
\end{tabular}




\begin{tabular}{cccccccccc}
\hline Index & Structure & Algorithm & $\begin{array}{c}\text { Euncti } \\
\text { on }\end{array}$ & $\begin{array}{c}\text { Hidden } \\
\text { activation }\end{array}$ & R $^{\mathbf{2}}$ & RMSE & \%RMSE & BIAS & \%BIAS \\
\hline 1 & MLP 10-4-1 & BFGS 192 & SOS & Exponential & 0.99 & 0.56 & 1.33 & 0.044 & 0.10 \\
\hline 2 & MLP 10-13-1 & BFGS 109 & SOS & Logistic & 0.99 & 0.58 & 1.38 & 0.043 & 0.10 \\
\hline 3 & MLP 10-9-1 & BFGS 79 & SOS & Logistic & 0.99 & 0.56 & 1.33 & 0.038 & 0.09 \\
\hline $\mathbf{4}$ & MLP 10-5-1 & BFGS 95 & SOS & Logistic & $\mathbf{0 . 9 9}$ & $\mathbf{0 . 5 5}$ & $\mathbf{1 . 3 0}$ & $\mathbf{0 . 0 2 9}$ & $\mathbf{0 . 0 6 1}$ \\
\hline 5 & MLP 10-8-1 & BFGS 157 & SOS & Logistic & 0.99 & 0.58 & 1.38 & 0.051 & 0.12 \\
\hline 6 & RBF 10-32-1 & RBFT & SOS & Gaussian & 0.95 & 0.61 & 14.52 & 0.12 & 0.285 \\
\hline 7 & RBF 10-27-1 & RBFT & SOS & Gaussian & 0.92 & 0.73 & 17.38 & 0.14 & 0.33 \\
\hline 8 & RBF 10-25-1 & RBFT & SOS & Gaussian & 0.95 & 0.60 & 14.28 & 0.091 & 0.21 \\
\hline 9 & RBF 10-26-1 & RBFT & SOS & Gaussian & 0.96 & 0.62 & 14.76 & 0.084 & 0.2 \\
\hline 10 & RBF 10-21-1 & RBFT & SOS & Gaussian & 0.94 & 0.71 & 16.90 & 0.11 & 0.26 \\
\hline
\end{tabular}

Table S8. Characteristics of RBF and MLP-based ANNs for the number of trees per hectare

ingrown beyond the DBH threshold of $12.5 \mathrm{~cm}$ over 10 years and associated goodness-of-fit

criteria for model evaluation. The superior model is shown in bold.

\begin{tabular}{cccccccccc}
\hline Index & Structure & Algorithm & $\begin{array}{c}\text { Error } \\
\text { Function }\end{array}$ & $\begin{array}{c}\text { Hidden } \\
\text { activation }\end{array}$ & R $^{\mathbf{2}}$ & RMSE & \%RMSE & BIAS & \%BIAS \\
\hline 1 & MLP 10-4-1 & BFGS 119 & SOS & Exponential & 0.99 & 0.56 & 1.32 & 0.029 & 0.059 \\
\hline 2 & MLP 10-13-1 & BFGS 219 & SOS & Logistic & 0.99 & 0.55 & 1.33 & 0.033 & 0.056 \\
\hline 3 & MLP 10-9-1 & BFGS 104 & SOS & Logistic & 0.99 & 0.55 & 1.54 & 0.030 & 0.065 \\
\hline $\mathbf{4}$ & MLP 10-5-1 & BFGS 95 & SOS & Logistic & $\mathbf{0 . 9 9}$ & $\mathbf{0 . 5 4}$ & $\mathbf{1 . 2}$ & $\mathbf{0 . 0 2 7}$ & $\mathbf{0 . 0 5 4}$ \\
\hline 5 & MLP 10-8-1 & BFGS 95 & SOS & Logistic & 0.99 & 0.59 & 1.85 & 0.028 & 0.098 \\
\hline 6 & RBF 10-32-1 & RBFT & SOS & Gaussian & 0.96 & 0.76 & 12.41 & -0.01 & -1.13 \\
\hline 7 & RBF 10-27-1 & RBFT & SOS & Gaussian & 0.95 & 0.73 & 14.76 & -0.02 & -2.11 \\
\hline 8 & RBF 10-25-1 & RBFT & SOS & Gaussian & 0.96 & 0.77 & 12.61 & 0.05 & 3.73 \\
\hline 9 & RBF 10-26-1 & RBFT & SOS & Gaussian & 0.94 & 0.78 & 15.19 & -0.9 & -0.60 \\
\hline 10 & RBF 10-21-1 & RBFT & SOS & Gaussian & 0.94 & 0.81 & 16.29 & -0.07 & -0.65 \\
\hline
\end{tabular}




\section{Figures}

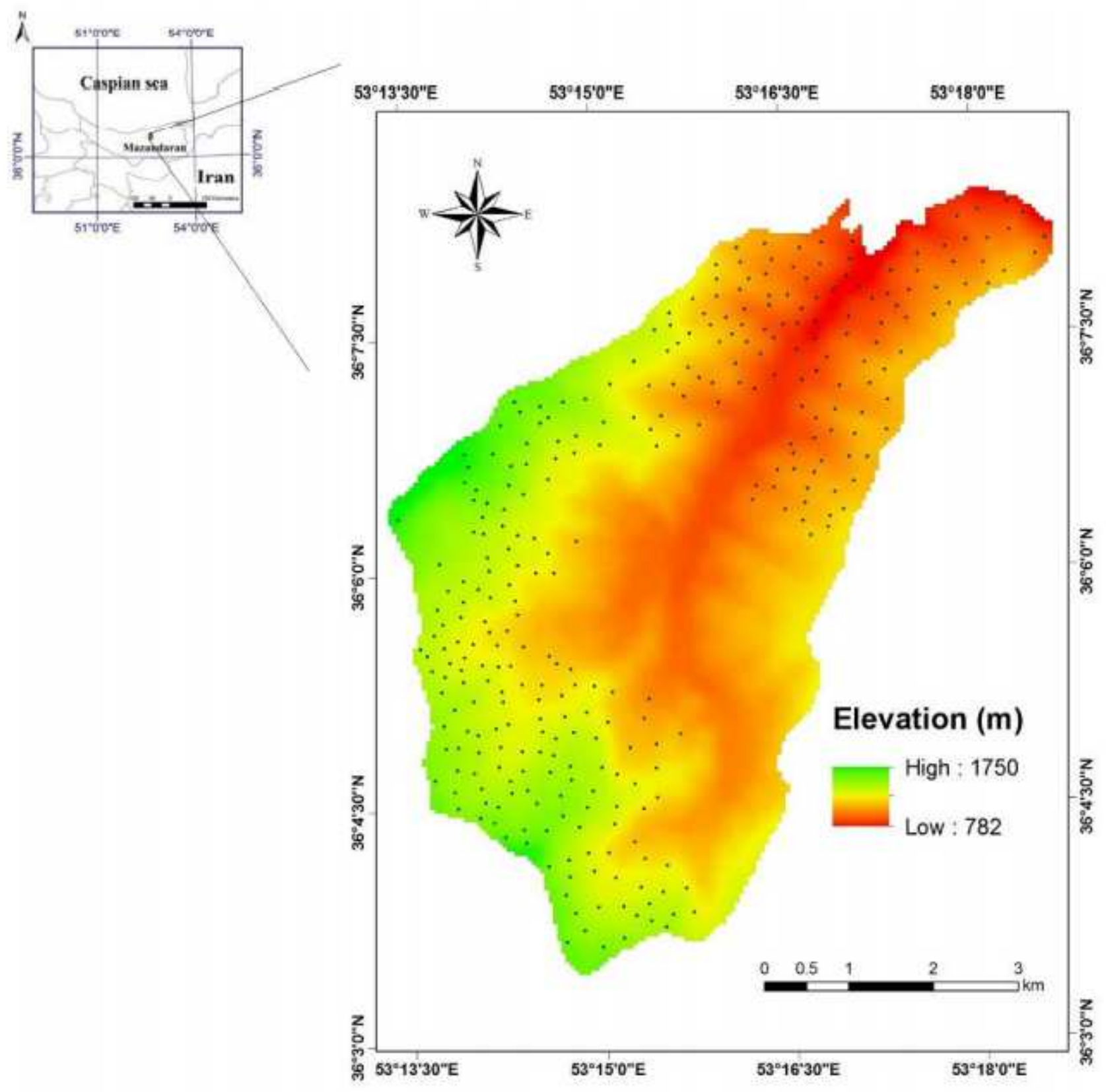

\section{Figure 1}

Overview of the study area in northern Iran and approximate location of plots used in this analysis. Variations in color indicate different elevations ( $m$, AMSL; see legend). 


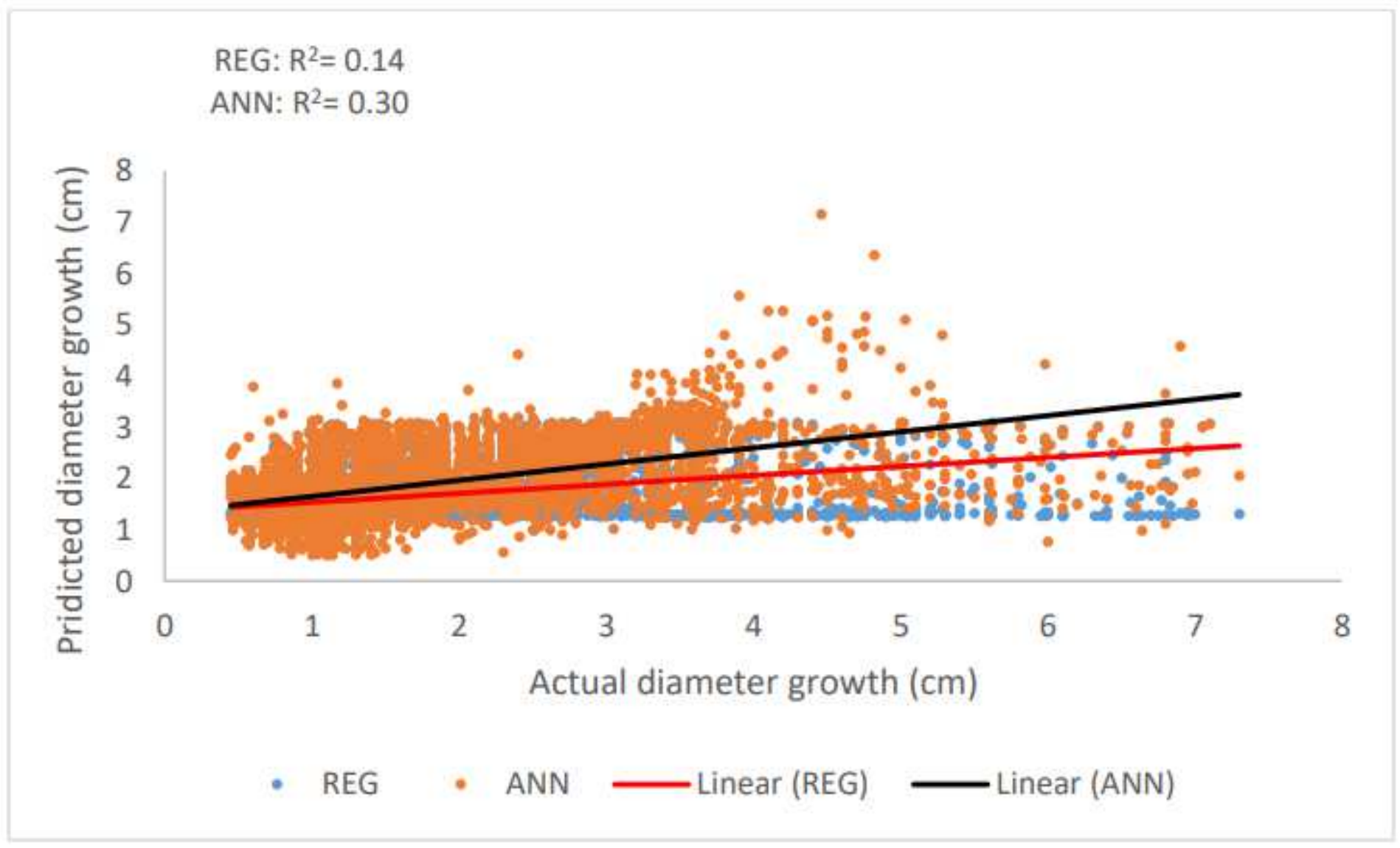

Figure 2

Graphical presentation of measured and predicted tree diameter growth by the parametric (mixed-effect regression (red line)) and non-parametric methods (ANN (black line)) 


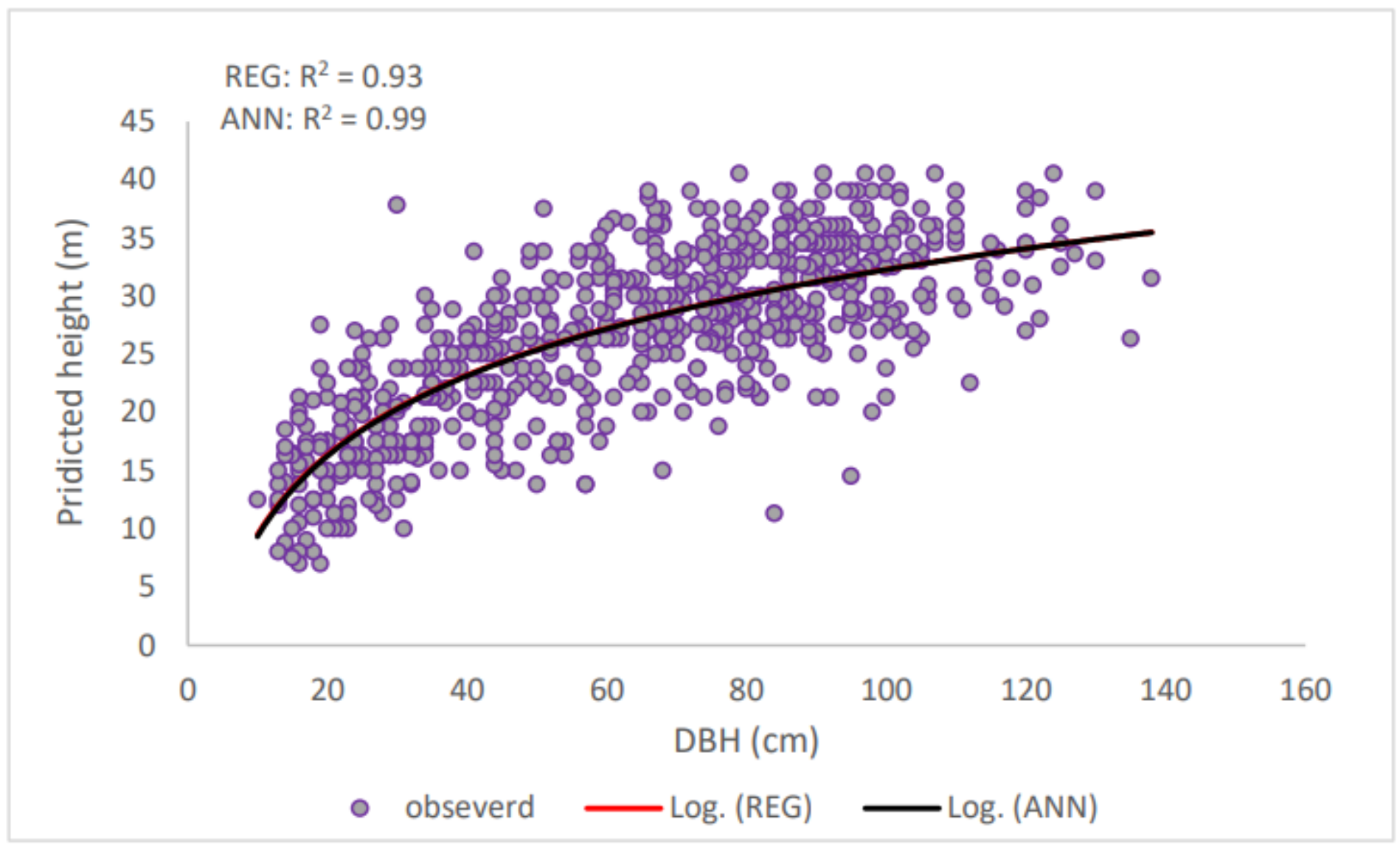

Figure 3

Regression model of diameter-height by the parametric (mixed-effect regression (red line)) and nonparametric methods (ANN (black line)) 
REG: $\mathrm{R} 2=0.70$

ANN: R2 $=0.30$

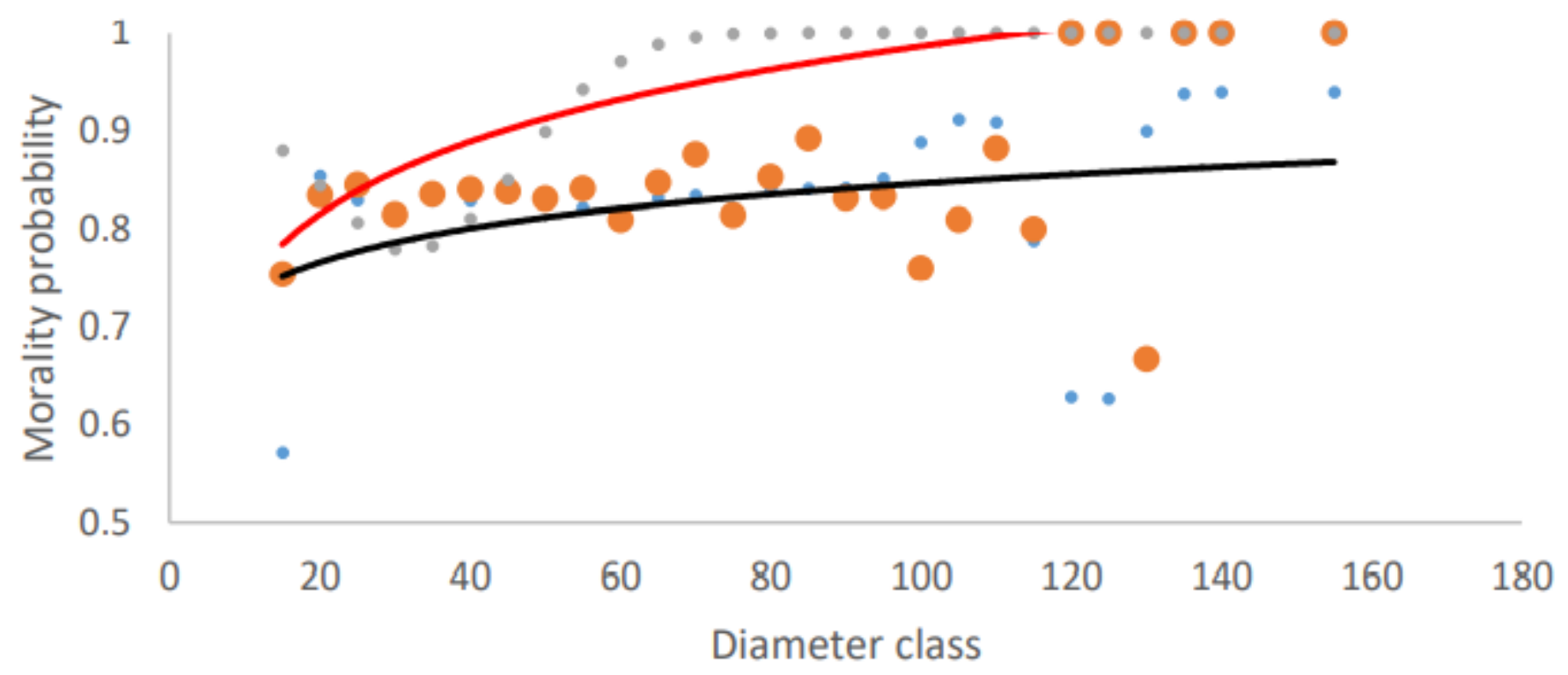

- ANN O Observed - REG — Log. (ANN) — Log. (REG)

Figure 4

Model of survival by the parametric (mixed-effect regression (red line)) and non-parametric methods (ANN (black line)) with observed probabilities by $5 \mathrm{~cm}$ diameter class. 


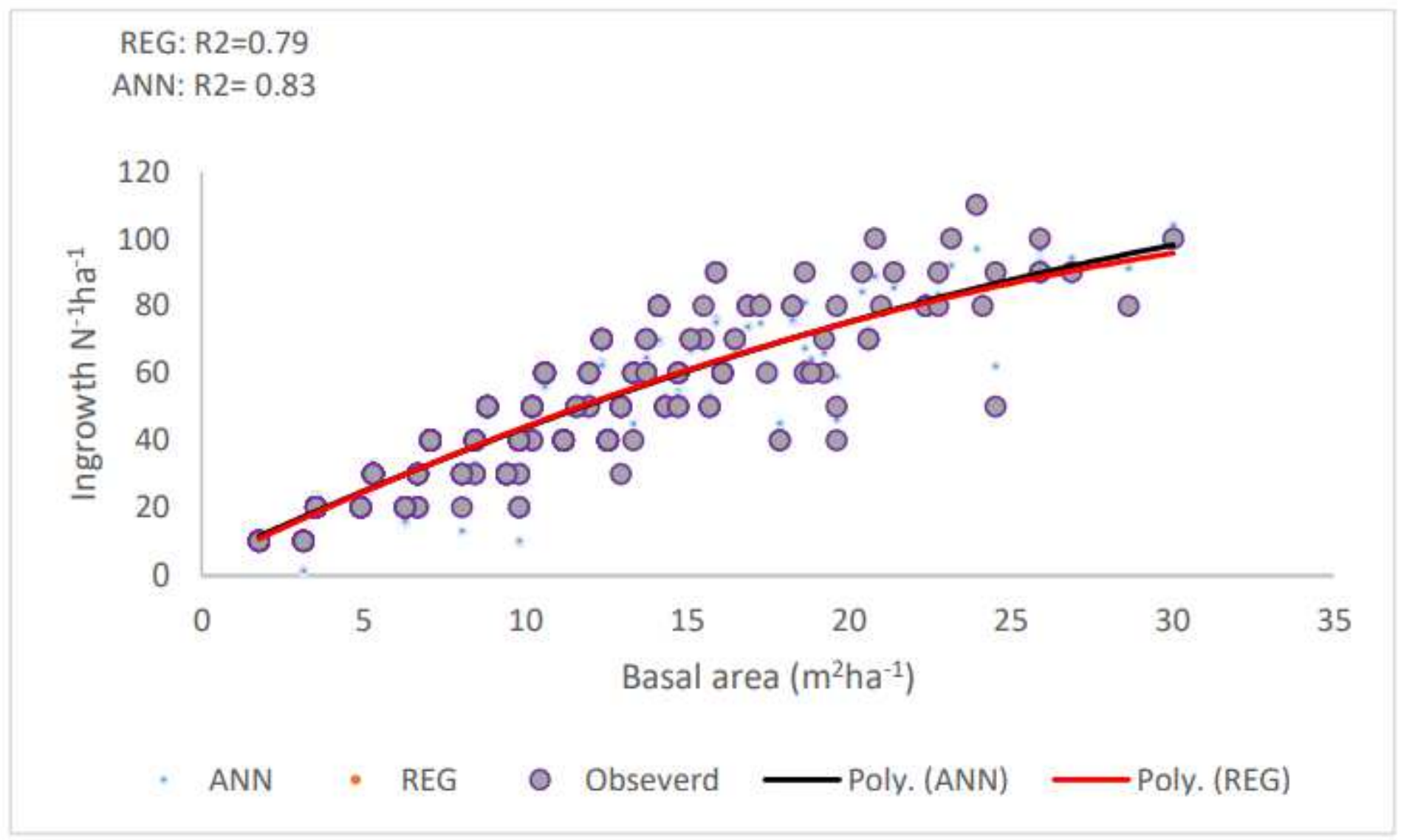

Figure 5

Predictions of the mixed-effects ingrowth model (Eqn. 11; number of trees passed the diameter class of $12.5 \mathrm{~cm}$ ) (red line)) and non-parametric methods (ANN (black line)) over total stand-level basal area (m2 ha-1) with observed values. 